\title{
BMJ Open SGLT-2 receptor inhibitors for treating patients with type 2 diabetes mellitus: a systematic review and network meta-analysis
}

\author{
Deepson S Shyangdan, ${ }^{1}$ Olalekan A Uthman, ${ }^{2}$ Norman Waugh ${ }^{3}$
}

To cite: Shyangdan DS, Uthman OA, Waugh N. SGLT-2 receptor inhibitors for treating patients with type 2 diabetes mellitus: a systematic review and network meta-analysis. BMJ Open 2016;6:e009417.

doi:10.1136/bmjopen-2015009417

- Prepublication history and additional material is available. To view please visit the journal (http://dx.doi.org/ 10.1136/bmjopen-2015009417).

Received 17 July 2015 Accepted 11 November 2015

CrossMark

For numbered affiliations see end of article.

\section{Correspondence to} Professor Norman Waugh; norman.waugh@warwick. ac.uk

\section{ABSTRACT}

Objective: Because of the lack of head-to-head trials, the aim was to indirectly compare sodium glucose transporter-2 (SGLT-2) inhibitors in the treatment of type 2 diabetes.

Design: Systematic review and network meta-analysis. Data sources: MEDLINE and EMBASE were searched from January 2005 to January 2015.

Eligibility criteria: Randomised controlled trials assessing the efficacy of SGLT-2 inhibitors in patients with type 2 diabetes inadequately controlled with diet and exercise alone or metformin monotherapy. Minimum duration 24 weeks. Indirect comparison was undertaken using Bayesian methods.

Results: In monotherapy, a greater proportion of patients achieved a glycated haemoglobin ( $\mathrm{HbA1C}$ ) level of $<7 \%$ on canagliflozin $300 \mathrm{mg}$ than on canagliflozin $100 \mathrm{mg}$ (risk ratio (RR) $0.72 \%, 95 \%$ credible intervals (Crl) $0.59 \%$ to $0.87 \%$ ) and dapagliflozin $10 \mathrm{mg}$ (RR $0.63,95 \% \mathrm{Crl} 0.48$ to 0.85 ) but there were no significant differences compared with either dose of empagliflozin. In monotherapy, canagliflozin $300 \mathrm{mg}$ reduced $\mathrm{HbA1c}$ more than other SGLT-2 inhibitors (mean difference ranged from $0.20 \%$ to $0.64 \%$ ). There were no significant differences in weight reduction. All the flozins reduced systolic blood pressure (SBP) more than placebo, ranging from a reduction of $6 \mathrm{~mm} \mathrm{Hg}$ with canagliflozin $300-$ $2.6 \mathrm{~mm} \mathrm{Hg}$ with empagliflozin $10 \mathrm{mg}$. In dual therapy with metformin, all flozins were more effective than placebo for achieving $\mathrm{HbA} 1 \mathrm{C}<7 \%$, and reducing HbA1c, weight and SBP. The proportions achieving $\mathrm{HbA} 1 \mathrm{c}$ level of $<7 \%$ were mostly similar. Canagliflozin $300 \mathrm{mg}$ reduced $\mathrm{HbA1c}$ more than the other drugs but this just reached statistical significance only against canagliflozin $100 \mathrm{mg}$ (MD 0.15, Crl 0.04 to 0.26 ).

Conclusions: There were few differences among the SGLT-2 inhibitors, but in monotherapy, the glucoselowering effect of canagliflozin $300 \mathrm{mg}$ is slightly greater than most other SGLT-2 inhibitors.

\section{INTRODUCTION}

The newest class of drugs for type 2 diabetes are the sodium glucose co-transporter 2

\section{Strengths and limitations of this study}

- In the absence of head-to-head comparisons of different sodium glucose transporter-2 inhibitors, a Bayesian network meta-analysis was used to compare the efficacy of the drugs.

- Studies were identified by a systematic search, and data abstraction and quality assessment of the studies were done independently by two authors.

- The study also includes the newer drugs in this class namely luseogliflozin, ipragliflozin and tofogliflozin.

- Safety data were not compared. The trials were for a maximum of 26 weeks duration.

receptor (SGLT-2) inhibitors. These reduce the reabsorption of renal-filtered glucose back into the bloodstream, thereby leading to loss of glucose in the urine. In the UK, the first three drugs in this class to reach the market, dapagliflozin, canagliflozin and empagliflozin, have been approved by the National Institute for Health and Care Excellence (NICE). ${ }^{1-3}$

In addition to the SGLT-2 transport system in the kidney, there is also a related transport system in the gut, SGLT-1. Most SGLT-2 inhibitors have no significant effect of SGLT-1, but one of the class, canagliflozin, does affect SGLT-1, and it has been suggested by Polidori $e t a l^{+}$that canagliflozin may reduce blood glucose by a dual action in both gut and kidney. However, that suggestion followed a very short-term study of canagliflozin in healthy individuals, and the gut effect was seen only with higher doses $(>200 \mathrm{mg})$.

A second study by Polidori and colleagues from Janssen Research and Development looked at the SGLT-1 effect in people with type 2 diabetes ${ }^{5}$ and found that canagliflozin $300 \mathrm{mg}$, but not $150 \mathrm{mg}$, reduced postprandial plasma glucose, by about $0.5 \mathrm{mmol} / \mathrm{L}$ (from graph) for about $2 \mathrm{~h}$ after 
administration, since it depends on an intestinal drug action not a systemic one. Would a change of that magnitude be enough to make a clinically meaningful difference in glycated haemoglobin (HbA1c), experienced once a day?

If the SGLT-1 effect is clinically significant in people with type 2 diabetes, then one might expect canagliflozin $300 \mathrm{mg}$ to be more potent in reducing HbAlc levels than other SGLT-2 inhibitors without the SGLT-1 effect. The usual starting dose of canagliflozin is $100 \mathrm{mg}$ once daily.

In the absence of head-to-head trials, the relative potencies can only be assessed by an indirect comparison by a network meta-analysis (NMA). We have therefore carried out two NMAs, one of five drugs in monotherapy and the other of four drugs in dual therapy with metformin. The aim was to determine whether the glucose-lowering effect of canagliflozin would be greater than that of other flozins without the SGLT-1 effect. Secondary aims were to compare effects on weight loss and blood pressure, and on proportions achieving HbAlc targets.

\section{METHODS}

\section{Information sources and search strategy}

A systematic search was undertaken to identify all the relevant studies. The searches were carried out in MEDLINE, MEDLINE In-process and EMBASE from January 2005 to September 2014 using search strategies given in online supplementary appendix S1. The search strategy was modified for other databases. The searches were updated in January 2015 and no new studies were found to be relevant. The reference lists of all the included studies were also checked for possible inclusions.

\section{Study selection}

Abstracts retrieved by the searches were screened for inclusion or exclusion. The studies were included if they met the following criteria: randomised controlled trial (RCT) assessing the efficacy of any SGLT-2 inhibitors in monotherapy in patients with type 2 diabetes inadequately controlled with diet and exercise, and in dual therapy in patients with inadequate control on metformin monotherapy. We compared the efficacies of only licensed doses, and in the data extraction tables, details of arms with other doses are omitted. Minimum duration was 24 weeks. The included studies should have reported either proportion of patients achieving an HbAlc target of $<7.0 \%$ or mean change in HbAlc from baseline to 24 weeks. We also sought changes in body weight and systolic blood pressure (SBP) from baseline to 24 weeks.

\section{Risk of bias assessment}

The quality of studies was assessed using the Cochrane Collaboration's tool for assessing risk of bias. ${ }^{6}$ The items assessed were (1) sequence generation, (2) allocation concealment, (3) blinding of outcome assessor, (4) incomplete outcome data and (5) selective outcome reporting. They were graded as unclear, high or low risk of bias.

\section{Study selection and data abstraction}

The studies were screened for inclusion and exclusion by one author and checked by a second. Any disagreements were resolved through discussion. There was no need for a third reviewer to resolve any disagreements regarding inclusion or exclusion. Data extraction forms were completed by one author and checked by a second author. Similarly, quality assessment was done by one author and checked by a second.

\section{Summary measures}

The proportion of patients achieving an HbA1c level target of $<7.0 \%$ at 24 weeks was summarised as risk ratio (RR). The treatment effects of continuous outcomes, that is, mean change in HbAlc, body weight or SBP from baseline to 24 weeks were summarised as weighted mean difference.

\section{Data synthesis and model implementation}

The treatment effects were assessed using a Bayesian approach to provide probability distributions for treatment effect parameters, with $95 \%$ credible intervals (CrIs) instead of $95 \%$ CI.

A Bayesian NMA method was used to analyse all the data, preserving randomised treatment effects within trials and accounting for correlation between comparisons with three arms. The freely available software, WinBUGS V.1.4.3, was used. The statistical heterogeneity in treatment effect estimates was estimated using between-study variance (ie, square root of the SD of underlying effects across trials) with $95 \% \mathrm{CrI}^{7}{ }^{7}$ Since our NMA included different trials comparing different SGLT-2 inhibitors, the distribution of treatment effect modifiers cannot only vary across trials for a particular comparison (as with standard pairwise meta-analysis, causing heterogeneity), but also between comparisons (causing inconsistency). If there is an imbalance in the distribution of treatment effect modifiers between different types of direct comparisons, the related indirect comparisons will be biased. ${ }^{8}$ To estimate inconsistency in the networks of evidence, we calculated the difference between indirect and direct estimates whenever indirect estimates could be constructed with a single common comparator. ${ }^{9}$ Inconsistency was defined as disagreement between direct and indirect evidence with a $95 \% \mathrm{CrI}$ excluding 0 for MD and 1 for RR. ${ }^{10}$ The model convergence was assessed using trace plots and the Brooks-Gelman-Rubin statistic. The analysis was undertaken using two Markov chains, which was ran simultaneously. The model was found to be converging adequately after 20000 samples for both chains. We ran the model further using 70000 samples and the results 
presented in the paper are based on these samples as we discarded the first 20000 samples. The probability of a treatment being the most effective (first best), the second best, and so on was also calculated. The results have been presented graphically with median ranks.

Both fixed-effect and random-effect models were used. The Bayesian Deviation Information Criterion (DIC) was used to compare the two models to see which was appropriate to compare treatment effects. The DIC measures the fit of the model while penalising it for the number of effective parameters. The model with the lowest DIC value was considered as the most appropriate NMA model. Based on DIC values obtained from the two models and also because of small number of studies available for the NMA, a fixed-effect model was chosen. Owing to small number of studies, it would have been difficult to estimate between-studies variance if a random-effect model was implemented.

We excluded the Bolinder 2012 trial $^{11}$ of dapagliflozin because it recruited patients with very good baseline HbA1c (mean 7.2\%) who would have less to gain. The primary outcome of the study was body composition and HbA1c was an exploratory variable. The low baseline HbAlc meant that the reduction in HbAlc was much smaller that in other trials, creating heterogeneity. However details are reported in tables and the Bolinder study was included in a sensitivity analysis.
The Henry 2012 trial $^{12}$ was unusual in that patients on no drug therapy were randomised straight to dual therapy with dapagliflozin and metformin (vs placebo and metformin) without trying monotherapy first. It is also included in a sensitivity analysis.

We also used the ipragliflozin trial by Kashiwagi et $a l^{24}$ only in sensitivity analysis because it had unusual features-an adjusted difference in HbAlc of $1.3 \%$, which was made up of a reduction of $0.87 \%$ on ipragliflozin and a rise of $0.38 \%$ on placebo, despite weight loss on placebo. More of the placebo group (52\%) had by chance had prior treatment with other glucose-lowering drugs than in the ipragliflozin arm $(35 \%, \mathrm{p}=0.045)$. No patients in the placebo group achieved HbAlc $<7.0 \%$, so in order to run the model we used $0.5 \%$ as achieving that.

We used a software called DigitizeIt to calculate SD from a published figure for an outcome mean change in HbAlc for a study ${ }^{13}$ assessing efficacy of canagliflozin in patients inadequately controlled with diet and exercise.

\section{RESULTS}

\section{Study selection and characteristics}

A total of 535 abstracts were retrieved from the searches (figure 1). After removing 73 duplicate articles, there were 462 articles left for title and abstract screening. A
Figure 1 Study selection flow diagram.

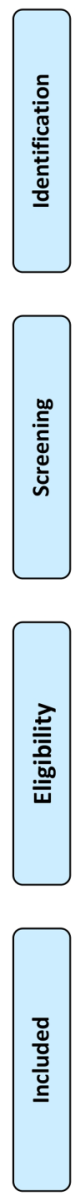


total of 417 articles were excluded on the basis of title and abstracts. Forty-five articles were included for fulltext screening. Thirteen trials ${ }^{12-24}$ met all the inclusion criteria and were included for the analysis. Table 1 gives characteristics of all the included studies. We have summarised baseline characteristics and results obtained in trials in tables 2 and 3 . We included six trials $^{111214151718 \text { of dapagliflozin, three trials }}{ }^{1319} 22$ of canagliflozin, two trials of empagliflozin ${ }^{16} 20$ one each of luseogliflozin, ${ }^{21}$ ipragliflozin ${ }^{24}$ and tofogliflozin. ${ }^{23}$

Eight trials ${ }^{13} \quad 15 \quad 17 \quad 18 \quad 20-23$ compared the efficacy of SGLT-2 inhibitors in monotherapy with placebo in patients inadequately controlled with diet and exercise. Six studies ${ }^{11} 1214161924$ compared flozins with placebo in dual therapy in patients failing to achieve glycaemic control on metformin alone.

Not all studies reported all the outcomes. Data on mean change in HbAlc were reported by all studies. Six monotherapy studies ${ }^{13} 1517182022$ reported the proportion achieving HbAlc of $<7.0 \%$ as did five dual therapy studies. $^{12} 14 \quad 16 \quad 1924$ For mean change in weight, seven $^{15} 1718$ 20-23 monotherapy and five ${ }^{12} 14161924$ dual therapy studies provided adequate information on efficacy of SGLT-2 inhibitors. For mean change in SBP, five monotherapy studies ${ }^{13} 15202223$ and three dual therapy studies $^{1619}{ }^{24}$ reported sufficient data. Stenlof $e t a^{13}$ did not report weight SDs for the two doses of canagliflozin, so this study could not be included. The weight data for canagliflozin $100 \mathrm{mg}$ come from Inagaki 2014 where the 100 and $200 \mathrm{mg}$ doses of canagliflozin were used. We excluded the $200 \mathrm{mg}$ dose since this is not a standard dose.

The networks comparing different SGLT-2 inhibitors for proportion of patients achieving HbAlc level of $<7 \%$ in monotherapy and dual therapy are shown in figures 2 and 3 .

As aforementioned, for other outcomes, some SGLT-2 inhibitors could not be included in the analysis due to inadequate information.

\section{Risk of bias of included trials}

Most of the included studies were high in quality, with low risk of bias. There were some studies where risk of bias could not be judged due to inadequate information. In this case, the risk of bias item was judged as unclear. Details of risk of bias are shown in figure 4. All the studies were funded by pharmaceutical companies.

\section{Monotherapy}

All SGLT-2 inhibitors were all significantly more effective than placebo for increasing proportion of patients achieving HbAlc $<7 \%$ (figure 5), reducing the mean change in HbAlc (\%) from baseline (figure 6), and reducing mean weight from baseline (figure 7). All SGLT-2 inhibitors reduced SBP compared with placebo, but this failed to reach statistical significance for dapagliflozin $10 \mathrm{mg}$, tofogliflozin 10 and $40 \mathrm{mg}$ because of wide CIs (figure 8).
Using canagliflozin $300 \mathrm{mg}$ as the baseline, patients on canagliflozin $100 \mathrm{mg} \quad(\mathrm{RR}=0.72,95 \% \mathrm{CrI} 0.59$ to $0.87)$ and dapagliflozin $10 \mathrm{mg}(\mathrm{RR}=0.63,95 \% \mathrm{CrI} 0.48$ to 0.85 ) were $28 \%$ and $37 \%$ less likely to have achieved HbAlc $<7 \%$ compared with those on canagliflozin $300 \mathrm{mg}$ (figure 5). The proportions of patients achieving HbAlc $<7 \%$ were similar among empagliflozin $10 \mathrm{mg}$, canagliflozin $100 \mathrm{mg}$ and dapagliflozin $10 \mathrm{mg}$.

Canagliflozin $300 \mathrm{mg}$ gave the largest reduction in HbAlc $(-1.23 \%)$ compared with placebo. Compared with the other flozins, some differences appeared not only statistically significant but also clinically meaningful: canagliflozin $100 \mathrm{mg}$ MD from canagliflozin $300 \mathrm{mg}=0.20$ (95\% CrI 0.05 to 0.36); empagliflozin $25 \mathrm{mg}$ (MD 0.37, $95 \%$ CrI 0.16 to 0.58 ); tofogliflozin $40 \mathrm{mg}$ (MD 0.39, $95 \%$ CrI 0.12 to 0.66 ); luseogliflozin $2.5 \mathrm{mg}$ ( $\mathrm{MD}=0.47,95 \%$ CrI 0.19 to 0.74 ); tofogliflozin $10 \mathrm{mg}$ (MD $0.46,95 \% \mathrm{CrI}$ 0.19 to 0.73$)$; empagliflozin $10 \mathrm{mg}(0.49,95 \%$ CrI 0.29 to 0.69 ); and dapagliflozin $10 \mathrm{mg}(\mathrm{MD}=0.64,95 \%$ CrI 0.45 to 0.83 ; figure 6 ).

Canagliflozin $100 \mathrm{mg}$ led to greater weight reduction than the other flozins; this reaching statistical significance was compared with empagliflozin $25 \mathrm{mg}$ (MD 0.85 , 95\% CrI 0.37 to 1.33); empagliflozin $10 \mathrm{mg}$ (MD 1.07, $95 \%$ CrI 0.59 to 1.56 ); tofogliflozin $10 \mathrm{mg}$ (MD 1.13, 95\% CrI 0.45 to 1.80 ); luseogliflozin $2.5 \mathrm{mg}$ (MD $1.20,95 \%$ CrI 0.63 to 1.77 ); and dapagliflozin $10 \mathrm{mg}$ (MD 1.37, 95\% CrI 0.92 to 1.83 ; figure 7 ).

SBP was reduced by all the flozins relative to placebo, with reductions ranging from $6.1 \mathrm{~mm} \mathrm{Hg}$ for canagliflozin $300 \mathrm{mg}$ to $2.6 \mathrm{~mm} \mathrm{Hg}$ for empagliflozin $10 \mathrm{mg}$, though (figure 8) in some cases CIs were wide and the reductions were not statistically significant. Among the flozins, only empagliflozin $10 \mathrm{mg}$ gave a difference that was statistically significant against canagliflozin (figure 8; $300 \mathrm{mg}$ : MD 3.55, 95\% CrI 0.60 to $6.44 ; 100 \mathrm{mg}$ : MD $2.56,95 \%$ CrI 0.30 to 4.75$)$.

For some comparisons, between-study variance was small suggesting no heterogeneity; however, the CrIs were wide which reflects the small number of studies available for pairwise comparisons. Analyses based on direct versus indirect comparisons showed no evidence of inconsistency between direct and indirect evidence in the network for all outcomes.

\section{Dual therapy}

For dual therapy, we undertook sensitivity analyses by including Kashiwagi et $a t^{24}$ (ipragliflozin), Henry et $a l^{12}$ (dapagliflozin) and Bolinder et $\mathrm{al}^{11}$ (dapagliflozin). Data for all the outcomes were not available from these studies. Therefore, a sensitivity analysis including the first two studies was undertaken for the proportions of patients achieving HbAlc level of $<7 \%$, mean change in HbA1c and mean change in weight. Bolinder et al ${ }^{11}$ study was included in the sensitivity analysis of mean change in HbAlc and weight. Kashiwagi et $a l^{24}$ was also included for sensitivity analysis of mean change in SBP. 
Table 1 Baseline characteristics of all included studies

\section{Study}

\section{Dapagliflozin}

Bailey et al $^{14}$

Setting: multicentre $(n=80)$

Design: four-arm, double-blind, placebo-controlled

RCT, dual therapy. Only $10 \mathrm{mg}$ arm included in

NMA

Follow-up: 24 weeks; 102 weeks

Bolinder et al ${ }^{11}$

Setting: multicentre $(n=40)$ in Bulgaria, Czech

Republic, Hungary, Poland and Sweden

Design: two-arm, double-blind, placebo-controlled

$\mathrm{RCT}$ in dual therapy

Duration: 24 weeks

\section{Ferrannini et al ${ }^{15}$}

Setting: multicentre $(n=85)$ in the USA, Canada,

Mexico and Russia

Design: double-blind, parallel-group,

placebo-controlled, phase 3 RCT in monotherapy

Duration: 24 weeks

Henry et al ${ }^{12}$

-Two studies (focusing on study 2)

Setting: multicentre $(n=131)$ - hospitals and clinics

in North America, Latin America, Europe and Asia

\section{$N: 534$}

Participants: patients with type 2 diabetes inadequately controlled with metformin ( $\geq 1500 \mathrm{mg} /$ day)

Age (years): dapa $10 \mathrm{mg}+$ metformin 52.7, SD 9.9; placebo+metformin 53.7, SD 10.3

HbA1c (\%): dapa $10 \mathrm{mg}+$ metformin 7.92 , SD 0.82 ; placebo+metformin 8.11, SD 0.96

$B M I\left(\mathrm{~kg} / \mathrm{m}^{2}\right)$ : dapa $10 \mathrm{mg}+$ metformin 31.2, SD 5.1; placebo+metformin 31.8 , SD 5.3

\section{N: 180}

Participants: patients with type 2 diabetes inadequately controlled with metformin ( $\geq 1500 \mathrm{mg} /$ day $)$

Age (years): dapa 10 mg+metformin 60.6, SD 8.2; placebo+metformin 60.8, SD 6.9

HbA1c (\%): dapa $10 \mathrm{mg}+$ metformin 7.19, SD 0.44; placebo+metformin 7.16 , SD 0.53 . Note the very low baseline level

BMI $\left(\mathrm{kg} / \mathrm{m}^{2}\right)$ : dapa $10 \mathrm{mg}+$ metformin 32.1, SD 3.9; placebo+metformin 31.7 , SD 3.9

\section{$N: 274$}

Participants: patients with type 2 diabetes mellitus

inadequately controlled with diet and exercise, naïve to treatment

Age (years): dapa 10 mg 50.6, SD 9.97; placebo 52.7,

SD 10.3

HbA1c (\%): dapa $10 \mathrm{mg} 8.01$, SD 0.96; placebo 7.84

SD 0.87

$B M I\left(\mathrm{~kg} / \mathrm{m}^{2}\right)$ : dapa $10 \mathrm{mg}+$ metformin 33.6, SD 5.4;

placebo+metformin 32.3, SD 5.5

N: 638

Participants: patients with type 2 diabetes inadequately

controlled with diet and exercise, naïve to treatment

Age (years): dapa $10 \mathrm{mg}+$ metformin 51.5, SD 10.1.
Interventions

$10 \mathrm{mg}$ dapa once daily+metformin

Comparator

Placebo+metformin

Outcomes

Primary outcomes: change in $\mathrm{HbA} 1 \mathrm{c}$ from baseline to

24 weeks

Other outcomes: change in FPG, change in total body weight, the proportion of patients achieving an $\mathrm{HbA} 1 \mathrm{c}$

$<7 \%$ at 24 weeks, change in $\mathrm{HbA} 1 \mathrm{c}$ percentage at week 24 for patients with a baseline $\mathrm{HbA} 1 \mathrm{c}$ of $9 \%$ or more and percentage change from baseline in bodyweight, and

decreases in bodyweight of $5 \%$ or more

Intervention

$10 \mathrm{mg}$ dapa once daily $(\mathrm{n}=89)+$ metformin

Comparator

Placebo $(n=91)+$ metformin

Outcomes

Primary outcome: change from baseline at week 24 in total body weight

Other outcomes: change from baseline at week 24 in waist circumference, total FM as measured by DEXA; proportion of patients achieving a body weight reduction

of at least $5 \%$ at week 24

Intervention

$10 \mathrm{mg}$ dapa $(\mathrm{n}=70)$

Comparator

Placebo $(n=75)$

Outcomes

Primary outcome: change from baseline in $\mathrm{HbA} 1 \mathrm{c}$ at week 24

Other outcomes: change from baseline at week 24 in FPG and body weight

Intervention

$10 \mathrm{mg}$ dapa+metformin $\mathrm{XR}(\mathrm{n}=211)$

Comparator

Placebo+metformin XR $(n=208)$

Continued 


Study
Design: double-blind, active controlled trials in dua
therapy

Duration: 24 weeks

\section{Ji et $a l^{17}$}

Setting: multicentre $(n=40)$ in China $(n=26)$, Korea $(n=5)$, Taiwan $(n=5)$ and India $(n=4)$ Design: double-blind, placebo-controlled,

parallel-group, RCT, monotherapy Duration: 24 weeks

Kaku et $a^{23} 2014$

Setting: multicentre $(n=N R)$ in Japan Design: double-blind, parallel-group, placebo-controlled RCT, monotherapy

Duration: 24 weeks

\section{Canagliflozin}

Lavalle-Gonzalez et al ${ }^{19}$

Setting: multicentre $(n=169)$ in 22 countries Design: double-blind, placebo-controlled and active-controlled trial, dual therapy Duration: 26 weeks
Participants and baseline data

placebo+metformin 52.7, SD 10.4

HbA1c (\%): dapa $10 \mathrm{mg}+$ metformin 9.1, SD 1.3; placebo +metformin 9.1, SD 1.3

$B M I\left(k g / m^{2}\right): N R$

\section{N: 393}

Participants: patients with type 2 diabetes naïve to drug treatment (prescription medication for diabetes including Chinese traditional medicines for diabetes, or prescription medication for diabetes for $<24$ weeks since diagnosis) Age (years): dapa $10 \mathrm{mg} \mathrm{51.2,} \mathrm{SD} \mathrm{9.89;} \mathrm{placebo} \mathrm{49.9,}$ SD 10.87

HbA1c (\%): dapa $10 \mathrm{mg} 8.28$, SD 0.95; placebo 8.35, SD 0.95

$\mathrm{BMI}\left(\mathrm{kg} / \mathrm{m}^{2}\right)$ : dapa $10 \mathrm{mg}$ 25.76, SD 3.43; placebo 25.93 , SD 3.64

$\mathrm{N}: 261$

Participants: patients with type 2 diabetes naïve to drug treatment

Age (years): dapa $10 \mathrm{mg}$ 57.5, SD 9.3; placebo 60.4,

SD 9.7

HbA1c (\%): dapa $10 \mathrm{mg} 7.46$, SD 0.61; placebo 7.50 ,

SD 0.63

$B M I\left(\mathrm{~kg} / \mathrm{m}^{2}\right)$ : dapa $10 \mathrm{mg} 26.6$, SD 4.52; placebo 25.22, SD 4.39

$N: 1284$

Participants: patients with type 2 diabetes inadequately controlled with metformin

Age (years): cana $100 \mathrm{mg}+$ metformin 55.5, SD 9.4; cana $300 \mathrm{mg}+$ +metformin 55.3 , SD 9.2; placebo+metformin 55.3 SD 9.8
Intervention/outcomes

Outcomes

Primary outcome: change from baseline in $\mathrm{HbA1c}$ at week 24

Secondary/other outcomes: change from baseline at week 24 in FPG and body weight Intervention

$10 \mathrm{mg}$ dapa $(\mathrm{n}=133)$

Comparator

Placebo $(n=132)$

Outcomes

Primary outcome: change from baseline in $\mathrm{HbA} 1 \mathrm{c}$ at week 24

Other outcomes: change from baseline in FPG at week 24; change from baseline in $2 \mathrm{~h} \mathrm{PPG}$ at week 24; change from baseline in total body weight at week 24; proportion of patients achieving $\mathrm{HbA} 1 \mathrm{c}$ levels of $<7 \%$ at week 24 Intervention

$10 \mathrm{mg}$ dapa $(\mathrm{n}=1)$

Comparator

Placebo $(n=132)$

Outcomes

Primary outcome: change from baseline in $\mathrm{HbA} 1 \mathrm{c}$ at week 24

Other outcomes: change from baseline in FPG and body weight at week 24; change from baseline in total body weight in patients with baseline BMI of $\geq 25 \mathrm{~kg} / \mathrm{m}^{2}$; fasting insulin and $\mathrm{C}$ peptide; seated SBP overall and in patients with baseline seated $\mathrm{SBP} \geq 130 \mathrm{mmHg}$; fasting lipids; proportion of patients achieving $\mathrm{HbA} 1 \mathrm{c}$ levels of $<7 \%$ at week 24 in patients with baseline $\mathrm{HbA1c} \geq 7 \%$ and proportion of patients discontinuing treatment due to lack of efficacy or rescued for failing to maintain FPG below prespecified rescue criteria after 24 weeks, and safety

Intervention

1. Cana $100 \mathrm{mg}+$ metformin $(n=368)$

2. Cana $300 \mathrm{mg}+$ metformin $(\mathrm{n}=367)$

Comparator

1. Placebo+metformin $(n=186)$

Outcomes 
Table 1 Continued

\section{Study}

Inagaki et $a^{22}$

Setting: multicenter $(n=31)$ in Japan

Design: double-blind placebo-controlled phase 3

parallel group trial

Duration: 24 weeks

Stenlof et $\mathrm{al}^{13}$

Setting: multicentre $(n=N R)$ in 17 countries

Design: double-blind, placebo-controlled, phase 3

T, monotherapy

Duration: 26 weeks

\section{Empa}

Haring et al ${ }^{16}$

Setting: multicentre $(n=148)$ in 12 countries

(Canada, China, France, Germany, India, Korea,

Mexico, Slovakia, Slovenia, Taiwan, Turkey and the

USA)

Design: double-blind placebo-controlled phase 3

\section{Participants and baseline data}

HbA1c (\%): cana $100 \mathrm{mg}+$ metformin 7.9 , SD 0.9; cana $300 \mathrm{mg}+$ metformin 7.9 , SD 0.9; placebo+metformin 8.0 SD 0.9 100 mg+metformin 32.4, SD 6.4; cana $\mathrm{HbA1c}$ level of <7.0\%; change in FPG, $2 \mathrm{~h}$ PPG and 300 mg+metformin 31.4, SD 6.3; placebo+metformin 31.1, SBP; change in body weight, triglycerides and HDL-C SD 6.1

N: 584

Participants: patients with type 2 diabetes inadequately controlled with diet and exercise and also on

antihypoglycaemic agents who underwent washout

(8 weeks and diet and exercise period with placebo run-in period) of the agent

Age (years): cana $100 \mathrm{mg} 55.1, \mathrm{SD} 10.8$; cana $300 \mathrm{mg}$

55.3, SD 10.2; placebo 55.7, SD 10.9

HbA1c (\%): cana $100 \mathrm{mg} 8.1$, SD 1.0; cana $300 \mathrm{mg} 0$

SD 1.0; placebo 8.0, SD 1.0

$B M I\left(\mathrm{~kg} / \mathrm{m}^{2}\right)$ : cana $100 \mathrm{mg} 31.3, \mathrm{SD} 6.6$; cana $300 \mathrm{mg}$

31.7, SD 6.0; placebo 31.8, SD 6.2

N: 272

Participants: patients with type 2 diabetes inadequately controlled with diet and exercise

Age (years): cana 100 mg 58.4, SD 10.4; placebo 58.2

SD 11.0

HbA1c (\%): cana $100 \mathrm{mg}$ 7.98, SD 0.73; placebo 8.04,

SD 0.70

BMI $\left(\mathrm{kg} / \mathrm{m}^{2}\right)$ : cana $100 \mathrm{mg} 25.59$, SD 4.20; placebo 25.85

SD 4.39

\section{N: 637}

Participants: patients with type 2 diabetes inadequately

controlled with diet and exercise and a stable

immediate-release metformin regimen

Age (years): empa $10 \mathrm{mg}+$ metformin 55.5 , SD 9.9; empa

$25 \mathrm{mg}+$ +metformin 55.6, SD 10.2; placebo+metformin 56 , SD 9.7

\section{ntervention/outcomes}

Primary outcome: change in $\mathrm{HbA} 1 \mathrm{c}$ from baseline to week 26

Other outcomes: proportion of patients achieving an Intervention

1. Cana $100 \mathrm{mg}(\mathrm{n}=195)$

2. Cana $300 \mathrm{mg}(\mathrm{n}=197)$

Comparator

1. Placebo $(n=192)$

Outcomes

Primary outcome: change in $\mathrm{HbA1c}$ from baseline to week 26

Other outcomes: proportion of patients reaching $\mathrm{HbA} 1 \mathrm{c}$ $<7.0 \%$; changes from baseline at week 26 in FPG and SBP; per cent changes from baseline in body weight, HDL-C and triglycerides

Intervention

1. $100 \mathrm{mg}$ canagliflozin $(n=90)$

Comparator

1. placebo $(n=93)$

Outcomes

Primary outcome: change from baseline in $\mathrm{HbA} 1 \mathrm{c}$ at week 24

Other outcomes: proportion of patients achieving $\mathrm{HbA} 1 \mathrm{c}$ target of $<7 \%$, change in FPG, PG at $2 \mathrm{~h}$ OGTT, per cent change in body weight, change in waist circumference, $\mathrm{BP}, \mathrm{HOMA}$, per cent change in lipids and safety

Intervention

1. $10 \mathrm{mg}$ empa+metformin $(\mathrm{n}=217)$

2. $25 \mathrm{mg}$ empa+metformin $(n=213)$

Comparator

1. Placebo+metformin $(n=207)$

Outcomes 


\section{Study}

RCT, dual therapy

Duration: 24 weeks

Roden et afo

Setting: multicentre $(n=124)$ in 9 countries

(Belgium, Canada, China, Germany, India, Japan,

Switzerland and USA)

Design: double-blind parallel-group RCT,

monotherapy

Duration: 24 weeks

Luseogliflozin

Seino et $a^{11}$

Setting: multicentre $(n=23)$ in Japan

Design: double-blind, placebo-controlled,

parallel-group, comparative, RCT, monotherapy

Duration: 24 weeks

Ipragliflozin

Kashiwagi et a ${ }^{24}$

Setting: multicentre $(n=34)$ in Japan

Design: double-blind, placebo-controlled RCT with

Participants and baseline data

Intervention/outcomes

HbA1c (\%): empa $10 \mathrm{mg}+$ metformin 7.94, SD 0.79; empa Primary outcome: change from baseline in $\mathrm{HbA1c}$ at $25 \mathrm{mg}$ +metformin 7.86 , SD 0.87 ; placebo+metformin 7.90 , week 24

SD 0.88

Other outcomes: change from baseline to week 24 in

BMI $\left(\mathrm{kg} / \mathrm{m}^{2}\right)$ : empa $10 \mathrm{mg}+$ metformin 29.1 , SD 5.5; empa $25 \mathrm{mg}+$ +metformin 29.7 , SD 5.7; placebo+metformin 28.7, SD 5.2

body weight and MDG; percentage of patients with baseline $\mathrm{HbA} 1 \mathrm{c} \geq 7.0 \%$ who had $\mathrm{HbA} 1 \mathrm{c}$ level $<7 \%$ at week 24; change from baseline in FPG, waist circumference, and SBP and DBP at week 24; percentage of patients with $>5 \%$ reduction in body weight at week 24; use of rescue medication; and safety

N: 899

Participants: patients with type 2 diabetes with no previous history to treatment (oral or injected hypoglycaemic agents 12 weeks prior to randomisation) Age (years): empa $10 \mathrm{mg}$ 56.2, SD 11.6; empa $25 \mathrm{mg}$ 53.8, SD 11.6; placebo 54.9, SD 10.9

HbA1c (\%): empa $10 \mathrm{mg} 7.87$, SD 0.88; empa $25 \mathrm{mg}$ 7.86, SD 0.85; placebo 7.91, SD 0.87

$B M I\left(\mathrm{~kg} / \mathrm{m}^{2}\right)$ : empa $10 \mathrm{mg}$ 28.3, SD 5.5; empa $25 \mathrm{mg}$ 28.2, SD 5.5; placebo 28.7, SD 6.2

$N: 158$

Participants: patients diagnosed with type 2 diabetes on stable diet therapy for $\geq 6$ weeks and not on any antidiabetic drugs

Age (years): luseo 2.5 mg 58.9, SD 10.1; placebo 59.6, SD 9.3

HbA1c (\%): luseo 2.5 mg 8.14, SD 0.91; placebo 8.17,

SD 0.80

BMI $(\mathrm{kg} / \mathrm{m}$

SD 4.19

\section{$N: 168$}

Participants: patients with type 2 diabetes of $\geq 12$ weeks

of duration, treated with metformin for $\geq 6$ weeks and with Intervention

1. $10 \mathrm{mg}$ empa $(n=224)$

2. $25 \mathrm{mg}$ empa $(n=224)$

Comparator

1. Placebo $(n=228)$

Outcomes

Primary outcome: change from baseline in $\mathrm{HbA} 1 \mathrm{c}$ at week 24

Other outcomes: change from baseline in bodyweight at week 24; change from baseline in SPB and DBP at week 24; proportion of patients with baseline $\mathrm{HbA} 1 \mathrm{c}$ level of at least $7 \%$ achieving $\mathrm{HbA} 1 \mathrm{c}$ level lower than $7.0 \%$ at week 24; change from baseline in FPG at week 24; proportion of patients with $>5 \%$ reduction in bodyweight at week 24 change from baseline in waist circumference at week 24 proportion of patients with uncontrolled BP at baseline who controlled their BP at week 24 (SBP $<130 \mathrm{~mm} \mathrm{Hg}$ and DBP $<80 \mathrm{~mm} \mathrm{Hg}$ ); and safety

Intervention

1. $2.5 \mathrm{mg}$ luseo $(\mathrm{n}=79)$

Comparator

1. Placebo $(n=79)$

Outcomes

Primary: change in $\mathrm{HbA} 1 \mathrm{c}$ from baseline to end of

treatment

Others: plasma glucose, insulin, glucagon, serum CPR intact

Intervention

1. Ipra $50 \mathrm{mg}+$ metformin $(\mathrm{n}=112)$

Comparator 


\section{Table 1 Continued}

\section{Study} Participants and baseline data

\section{Intervention/outcomes}

28 weeks open-label extension

Duration: 24 weeks with a 28 weeks open-label

an $\mathrm{HbA1c}$ level of $7.4-9.9 \%$ and $\mathrm{BMI}$ of $20-45 \mathrm{~kg} / \mathrm{m}^{2}$

1. Placebo+metformin $(n=56)$

extension

9.24

9.24

Primary outcome: change in $\mathrm{HbA} 1 \mathrm{c}$ from baseline to end

0.738

BMI $\left(\mathrm{kg} / \mathrm{m}^{2}\right)$ : ipra $50 \mathrm{mg} 25.96, \mathrm{SD} 4.410$; placebo 25.47 SD 3.092

Togoliflozin

Kaku et $a^{P^{3}}$

Setting: multicentre $(n=33)$ in specialists and

non-specialists hospital in Japan

N: 235

Participants: patients with type 2 diabetes naïve to drug

therapy but, only treated with diet and exercise for

$\geq 8$ weeks before screening, $\mathrm{HbA} 1 \mathrm{c}$ level of $\geq 7.3 \%$ to

$<10.3 \%$, BMI of $\geq 18.5$ to $<45 \mathrm{~kg} / \mathrm{m}^{2}$, per cent changes in

$\mathrm{HbA} 1 \mathrm{C}$ and body weight from the provisional registration

visit to the final registration visit of $\leq 10 \%$ and $<5 \%$,

respectively, controlled $\mathrm{BP}$ and those requiring

antihypertensives only those who did not require changing of their dosing regimen. Patients using other antidiabetic drugs were eligible if they had stopped their drug

$\geq 8$ weeks before the provisional registration. (HbA1c reported in Japan Diabetes Society or JDS units but, converted to NGSP units)

Age (years): tofo $10 \mathrm{mg} \mathrm{58.6,} \mathrm{SD} \mathrm{9.8;} \mathrm{tofo} 20 \mathrm{mg} \mathrm{56.6,}$ SD 10.2; tofo $40 \mathrm{mg} \mathrm{57.0,} \mathrm{SD} \mathrm{9.1;} \mathrm{placebo} \mathrm{56.8,} \mathrm{SD} 9.9$ of treatment

Other outcomes: body weight, waist circumference, FPG FSI, plasma leptin, and adiponectin levels, HOMA-R and HOMA- $\beta$ and safety outcomes

Intervention

1. Tofo $10 \mathrm{mg}(\mathrm{n}=59)$

2. Tofo $20 \mathrm{mg}(\mathrm{n}=60)$

3. Tofo $40 \mathrm{mg}(\mathrm{n}=59)$

Comparator

1. Placebo $(n=57)$

Outcomes

Primary outcome: change in $\mathrm{HbA} 1 \mathrm{c}$ from baseline to end of treatment

Other outcomes: $24 \mathrm{~h}$ FPG, $2 \mathrm{~h}$ PPG, fasting and $2 \mathrm{~h}$ postprandial insulin, glycoalbumin, body weight, pancreatic $\beta$-cell function (HOMA- $\beta$ ), insulin resistance (HOMA-R) and Matsuda index, insulin, serum lipid levels, adiponectin, BP and waist circumference, and safety outcomes HbA1c (\%): tofo $10 \mathrm{mg} 8.45$, SD 0.75 ; tofo $20 \mathrm{mg} 8.34$ SD 0.81 ; tofo $40 \mathrm{mg} 8.37$, SD 0.77 ; placebo 8.41 , SD 0.78

$B M I\left(\mathrm{~kg} / \mathrm{m}^{2}\right)$ : tofo $10 \mathrm{mg} 25.07, \mathrm{SD} 3.53$; tofo $20 \mathrm{mg}$ 24.99, SD 4.55; tofo $40 \mathrm{mg} 25.78$, SD 4.10; placebo 26.00, SD 4.11

BMI, body mass index; cana, canagliflozin; CPR, C peptide immunoreactivity; dapa, dapagliflozin; DBP, diastolic blood pressure; DEXA, dual-energy X-ray absorptiometry; empa, empagliflozin;

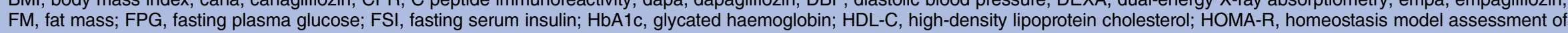
insulin resistance; HOMA- $\beta$, homeostasis model assessment of $\beta$-cell function; ipra, ipragliflozin; luseo, luseogliflozin; NMA, network meta-analysis; NR, not reported; OGTT, oral glucose tolerance test; PPG, postprandial glucose; RCT, randomised controlled trial; SBP, systolic blood pressure; tofo, tofogliflozin. 


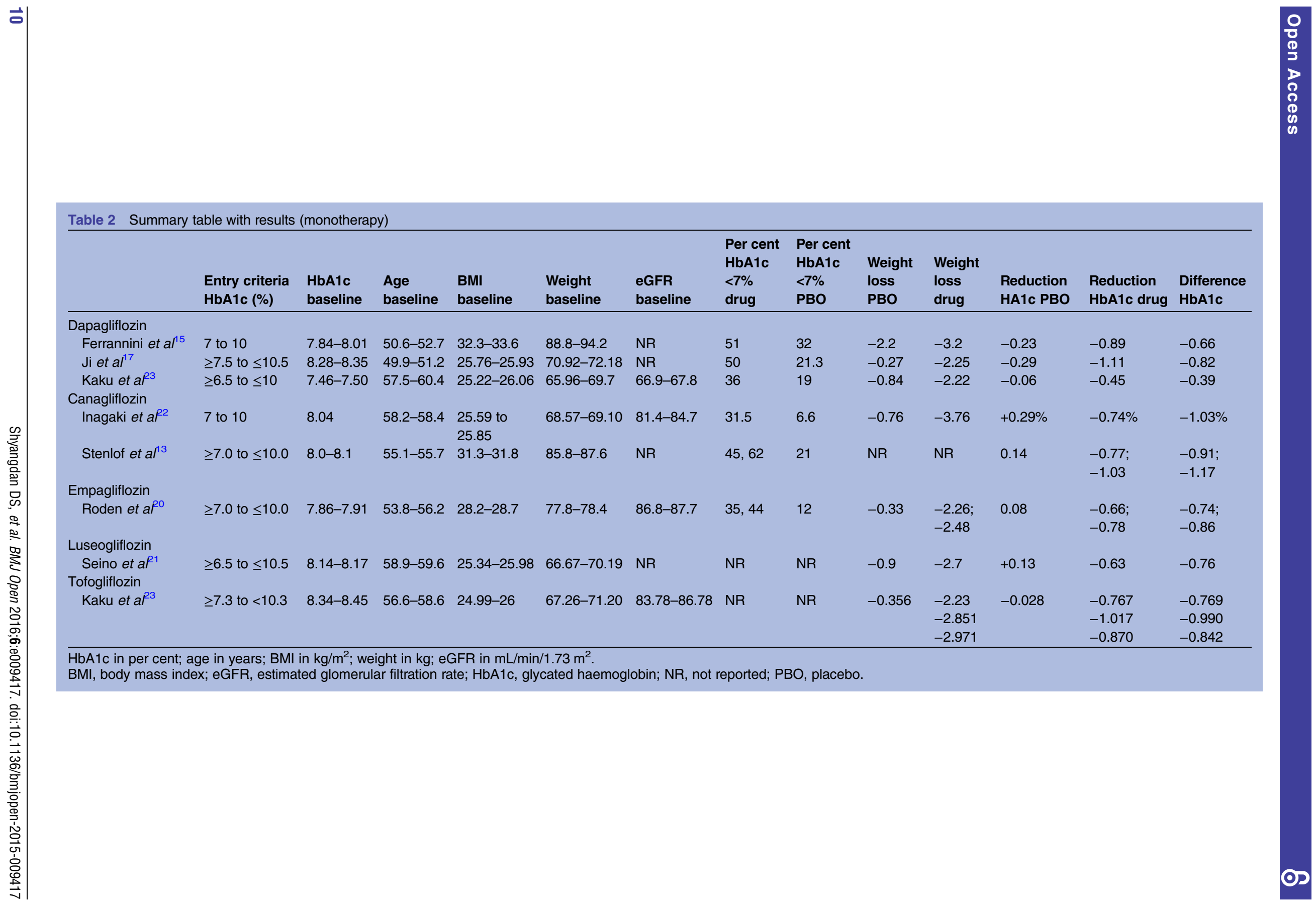

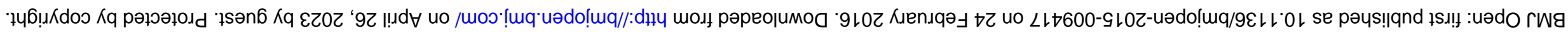




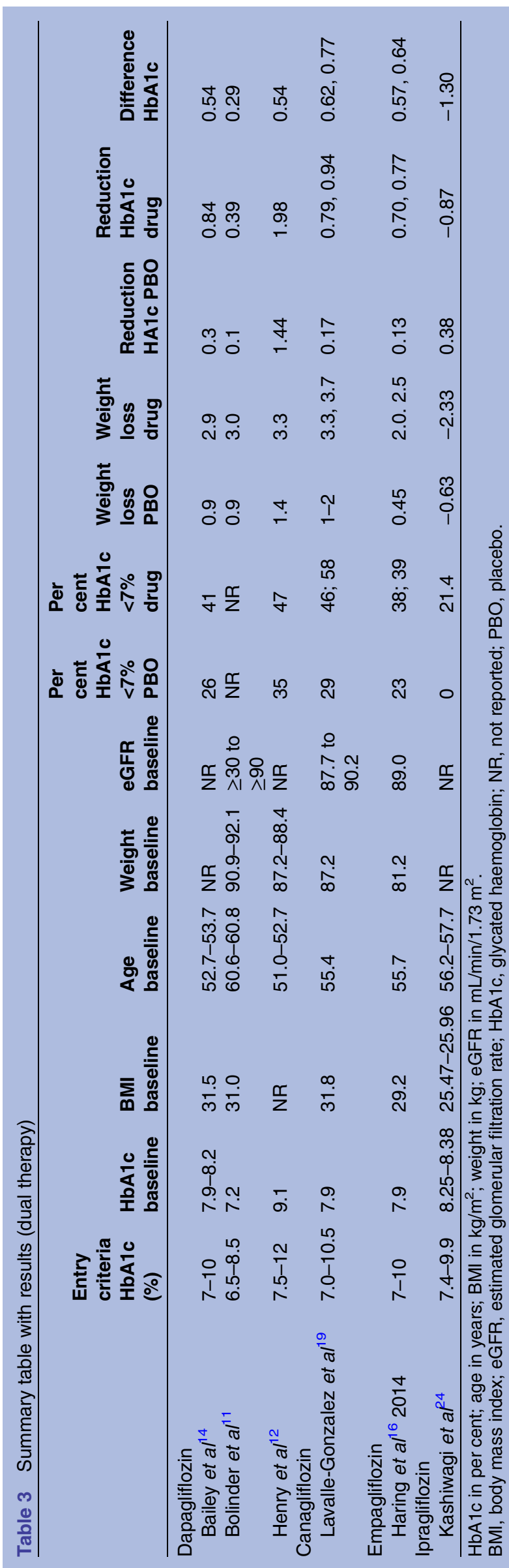

All SGLT-2 inhibitors were significantly more effective than placebo for achieving HbAlc $<7 \%$ (figure 9), reducing HbAlc (\%) from baseline (figure 10), weight loss (figure 11) and reducing SBP (figure 12). The results were slightly different when the trials by Kashiwagi $e t a l^{24}$ and Henry et $a l^{12}$ were included, as discussed later.

Empagliflozin 25 and $10 \mathrm{mg}$, and canagliflozin $300 \mathrm{mg}$ had higher proportions of patients achieving HbAlc $<7 \%$ than canagliflozin $100 \mathrm{mg}$ and dapagliflozin $10 \mathrm{mg}$ (figure 9).

Canagliflozin $300 \mathrm{mg}$ gave the greatest reduction in HbAlc $(0.77 \%)$, but the differences were small (vs canagliflozin $100 \mathrm{mg}(\mathrm{MD}=0.15,95 \% \mathrm{CrI} 0.04$ to 0.26$)$ and dapagliflozin $10 \mathrm{mg}(\mathrm{MD}=0.23,95 \% \mathrm{CrI}-0.01$ to 0.47 ); figure 10). There were no statistically significant differences between the two doses of canagliflozin and the two doses of empagliflozin.

In sensitivity analyses compared with placebo (figure 13), ipragliflozin $50 \mathrm{mg}$ showed the greatest reduction in HbA1c (1.25\%) followed by canagliflozin $300 \mathrm{mg}$ $(0.77 \%)$, empagliflozin $25 \mathrm{mg}(0.64 \%)$, canagliflozin $100 \mathrm{mg} \quad(0.62 \%)$, empagliflozin $10 \mathrm{mg} \quad(0.57 \%)$ and dapagliflozin $10 \mathrm{mg}(0.54 \%)$, but as noted above, we have reservations about the Kashiwagi study.

All the drugs were associated with greater weight loss than placebo, ranging from a reduction of $1.63 \mathrm{~kg}$ on empagliflozin $10 \mathrm{mg}$ to $2.5 \mathrm{~kg}$ on canagliflozin $300 \mathrm{mg}$ (figure 11). Canagliflozin $300 \mathrm{mg}$ was statistically significantly better in reducing weight than empagliflozin $10 \mathrm{mg}$ (MD $0.88 \mathrm{~kg}, 95 \%$ CrI 0.16 to 1.61 ) and ipragliflozin $50 \mathrm{mg}(0.81 \mathrm{~kg}, 95 \% \mathrm{CrI} 0.03$ to 1.58 ; figure 14$)$.

For mean change in SBP, inclusion of the Kashiwagi (ipragliflozin) and Henry studies (dapagliflozin) caused contrasting results. By excluding them, all flozins (canagliflozin 300 and $100 \mathrm{mg}$, empagliflozin 25 and $10 \mathrm{mg}$ ) were associated with significant reduction in SBP compared with placebo, but there were no significant differences among them (figure 12). By including the two studies, all flozins including dapagliflozin and ipragliflozin were found to be significantly better than placebo, but less so than without them, and there were differences between them. Dapagliflozin $10 \mathrm{mg}$ was found to be significantly better than all other flozins, and ipragliflozin $50 \mathrm{mg}$, canagliflozin $300 \mathrm{mg}$ and empagliflozin $25 \mathrm{mg}$ were found to be better than empagliflozin $10 \mathrm{mg}$ (figure 15).

For some comparisons, between-study variance was small suggesting no heterogeneity; however, the CrIs were wide which reflects the small number of studies available for pairwise comparisons. Analyses based on direct versus indirect comparisons showed no evidence of inconsistency between direct and indirect evidence in the network for all outcomes.

The effect of including the Bolinder trial was that the mean reduction in HbA1c on dapagliflozin became significantly less than with canagliflozin $300 \mathrm{mg}$, empagliflozin $25 \mathrm{mg}$ and canagliflozin $100 \mathrm{mg}$. The findings for weight did not change. However, as noted earlier, 


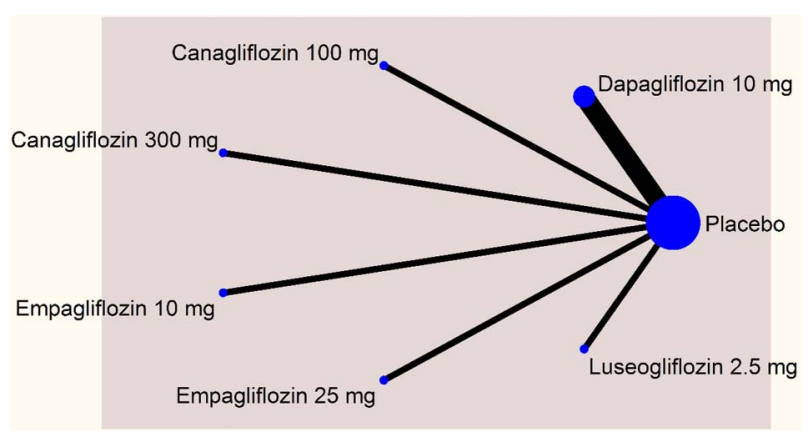

Figure 2 Network plot-monotherapy (mean change in glygated haemoglobin).

patients in the Bolinder trial started at a much lower baseline HbAlc and had a much smaller mean reduction in HbAlc.

A sensitivity analysis including the Henry and Kashiwagi trials is shown in figure 16. The CIs around ipragliflozin are very wide because no patients in the placebo group achieved HbA1c under 7\%.

\section{DISCUSSION}

\section{Statement of principal findings}

Our NMA showed few differences among the flozins. In monotherapy, canagliflozin $300 \mathrm{mg}$ gave the largest reduction in HbAlc among the SGLT-2 inhibitors in patients with type 2 diabetes with inadequate glycaemic control on diet and exercise alone. However, treatment with canagliflozin would be started with $100 \mathrm{mg}$ and only increased in those with an insufficient response to that dose. Those with a poor response to the $100 \mathrm{mg}$ dose might also have a poor response to $300 \mathrm{mg}$.

In monotherapy, the reduction in weight was greatest with canagliflozin $100 \mathrm{mg}(-3 \mathrm{~kg})$. All the SGLT-2 inhibitors reduced SBP, though wide CIs meant that differences were not always statistically significant. In dual therapy with metformin, canagliflozin $300 \mathrm{mg}$ gave the greatest reductions in HbAlc $(0.77 \%)$ and weight $(-2.5 \mathrm{~kg})$, and these differences were sometimes statistically significant but not clinically so. There were no statistically significant differences among the drugs in reducing SBP.
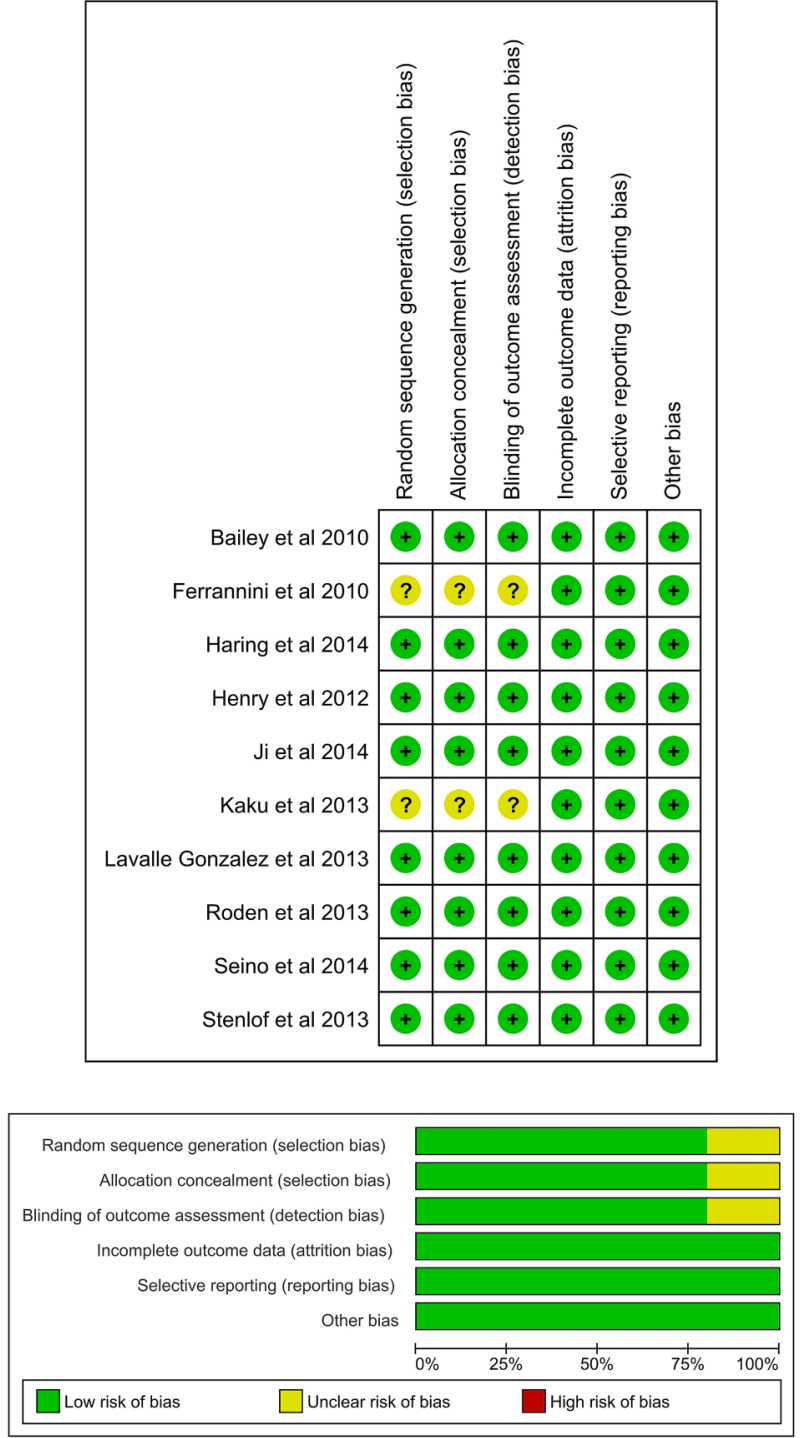

Figure 4 Risk of bias.

\section{Strengths and limitations}

We compared the efficacy of SGLT-2 inhibitors in patients with type 2 diabetes inadequately controlled with diet and exercise or metformin monotherapy. The relevant studies were identified systematically. Data extraction and
Figure 3 Network plot-dual therapy $(\%$ of patients achieving glycated haemoglobin $<7 \%$ ).

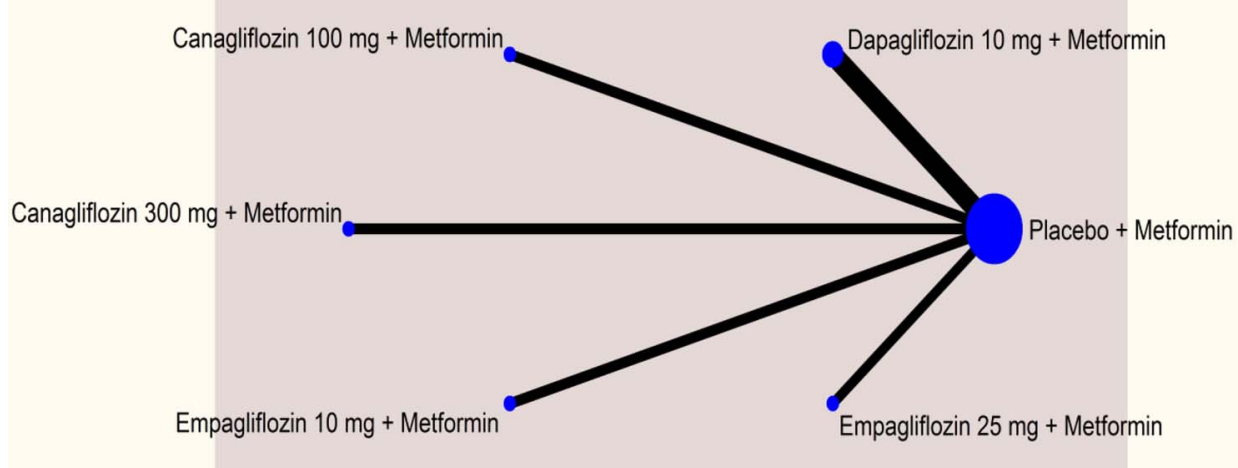




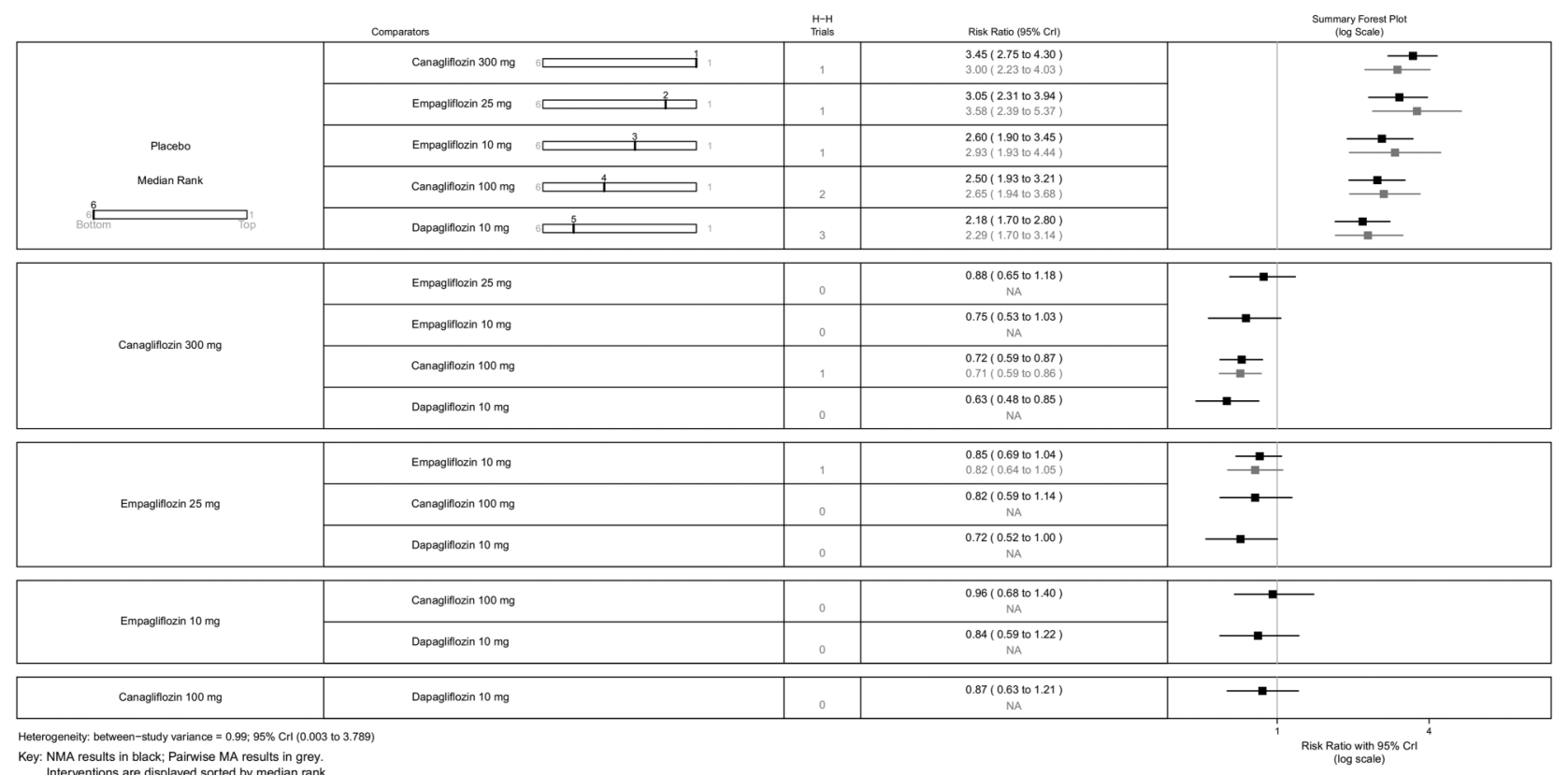

Figure 5 Proportion of patients achieving $\mathrm{HbA} 1 \mathrm{c}$ level of $<7 \%$-monotherapy. HbA1c, glycated haemoglobin; NA, not available; NMA, network meta-analysis.

quality assessment of the included studies were checked systematically by two authors. Most of the included studies were high in quality but the risk of bias in some studies could not be judged due to lack of information.

Our study has strengths. Unlike conventional pair wise meta-analysis, our NMAs allow for comparisons between SGLT-2 inhibitors that have not been compared head-to-head in RCTs. In addition, combining direct and indirect evidence in NMA offer additional precision by 'borrowing strength' from indirect evidence. ${ }^{25}$ Another strength of the NMA is that it treats all comparators as separate treatments while gaining statistical power from including all available data. ${ }^{26}$

The main limitation is the lack of head-to-head trials. The number of trials contributing evidence to several comparisons in the network was small.

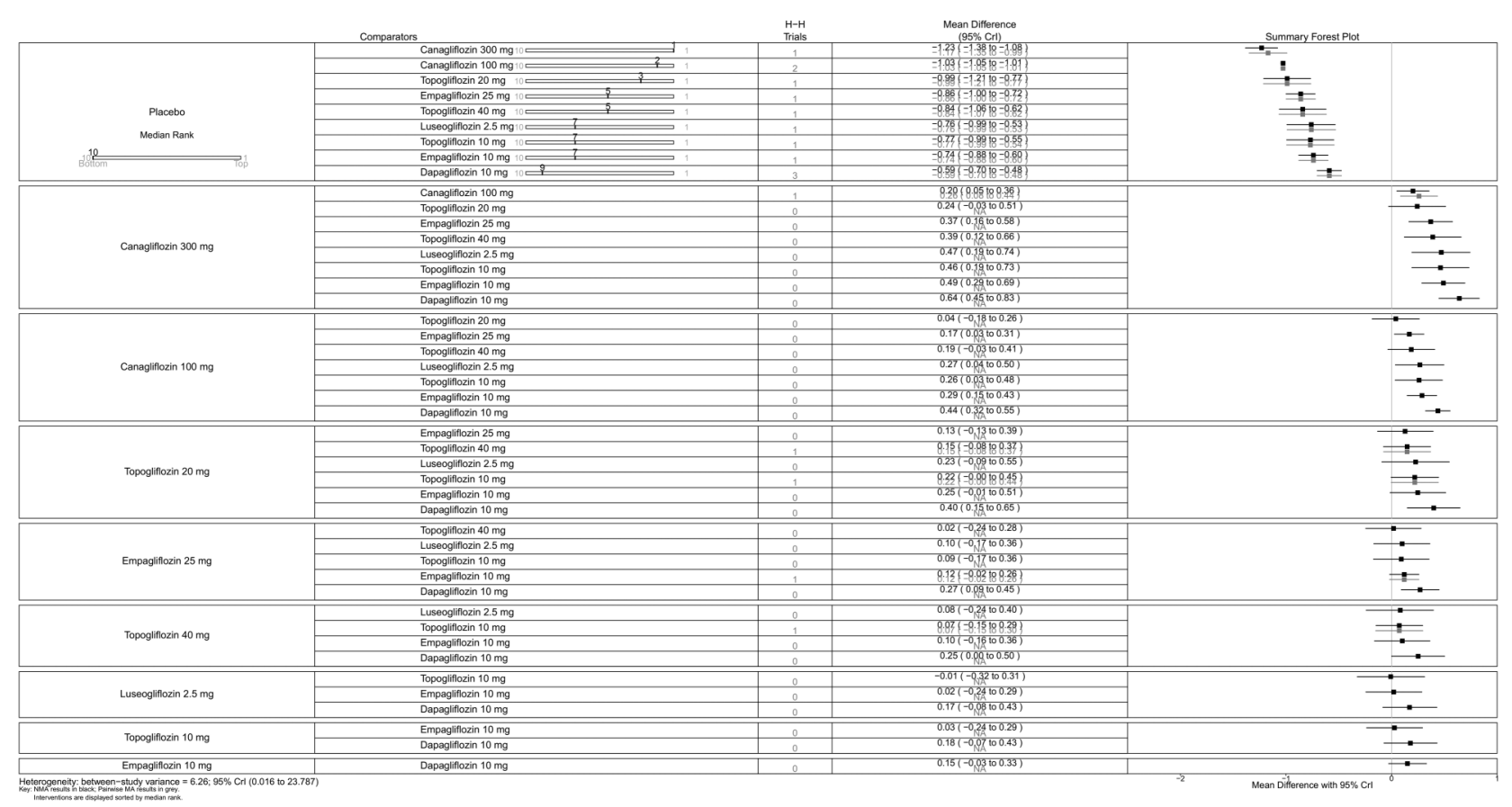

Figure 6 Mean change in $\mathrm{HbA1c}(\%)$-monotherapy. HbA1c, glycated haemoglobin; NA, not available; NMA, network meta-analysis. 


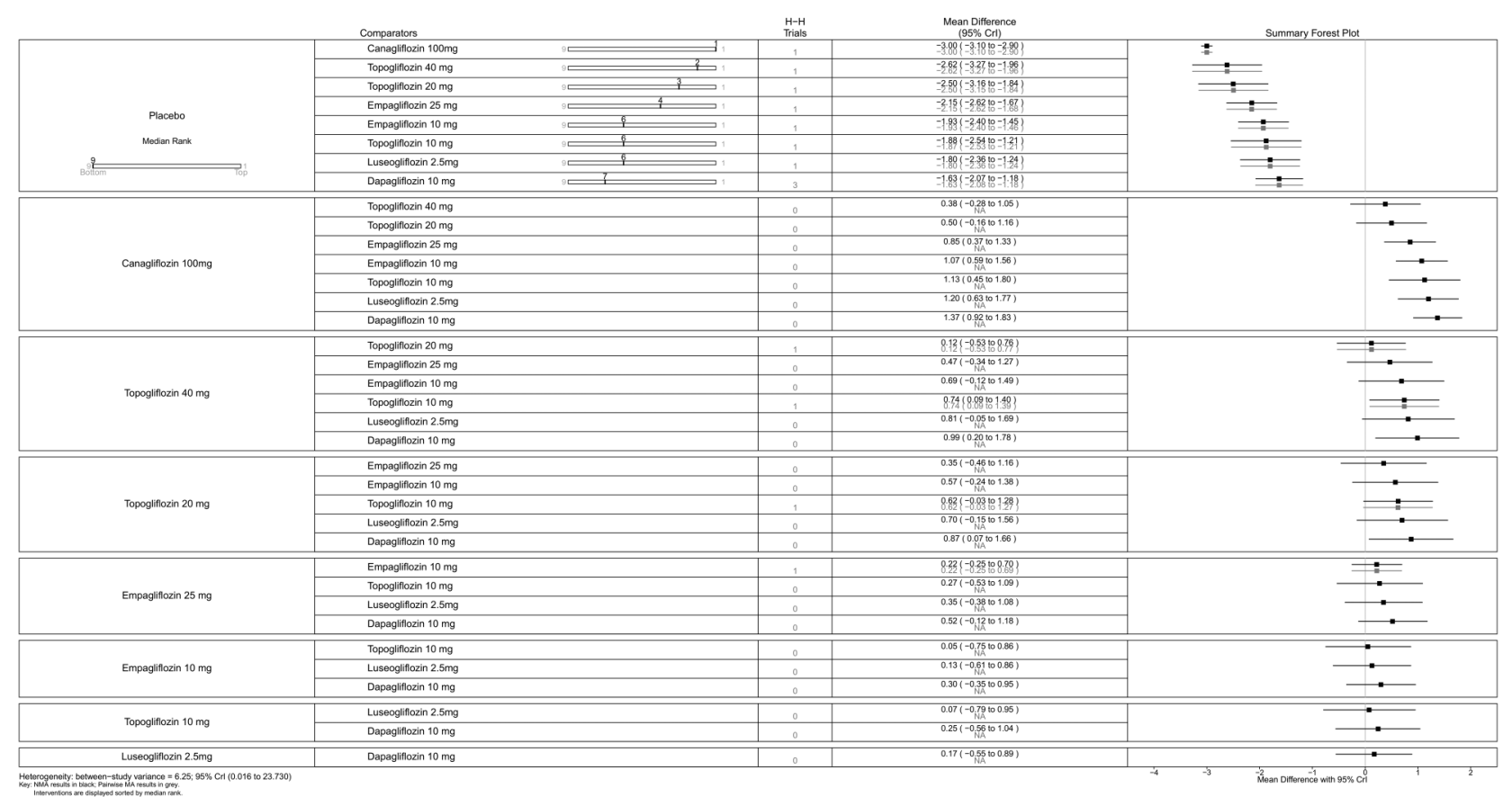

Figure 7 Mean change in weight $(\mathrm{kg})$ —monotherapy. NA, not available; NMA, network meta-analysis.

Another limitation is that in the trials, patients were randomised to canagliflozin $300 \mathrm{mg}$, whereas in clinical practice, they would be tried on $100 \mathrm{mg}$ daily first.

One of the three dapagliflozin trials, by Kaku et $a l^{18}$ recruited patients with a baseline HbAlc of only $7.5 \%$, and not surprisingly their reduction in $\mathrm{HbAlc}$ was less $(0.39 \%)$ than in most other trials. Exclusion of this study would raise the mean reduction on dapagliflozin to $0.75 \%$ (Astra Zeneca corporate communication, at NICE Appraisal Committee 25 November 2015).

Another factor to be considered is that in the dapagliflozin trials, HbA1c fell in the placebo groups, by $0.29 \%$ and $0.23 \%$ in the Ji $e t a l^{17}$ and Ferrannini $e t a l^{15}$ trials. In the Ferrannini trial, weight fell significantly by $2.2 \mathrm{~kg}$. In

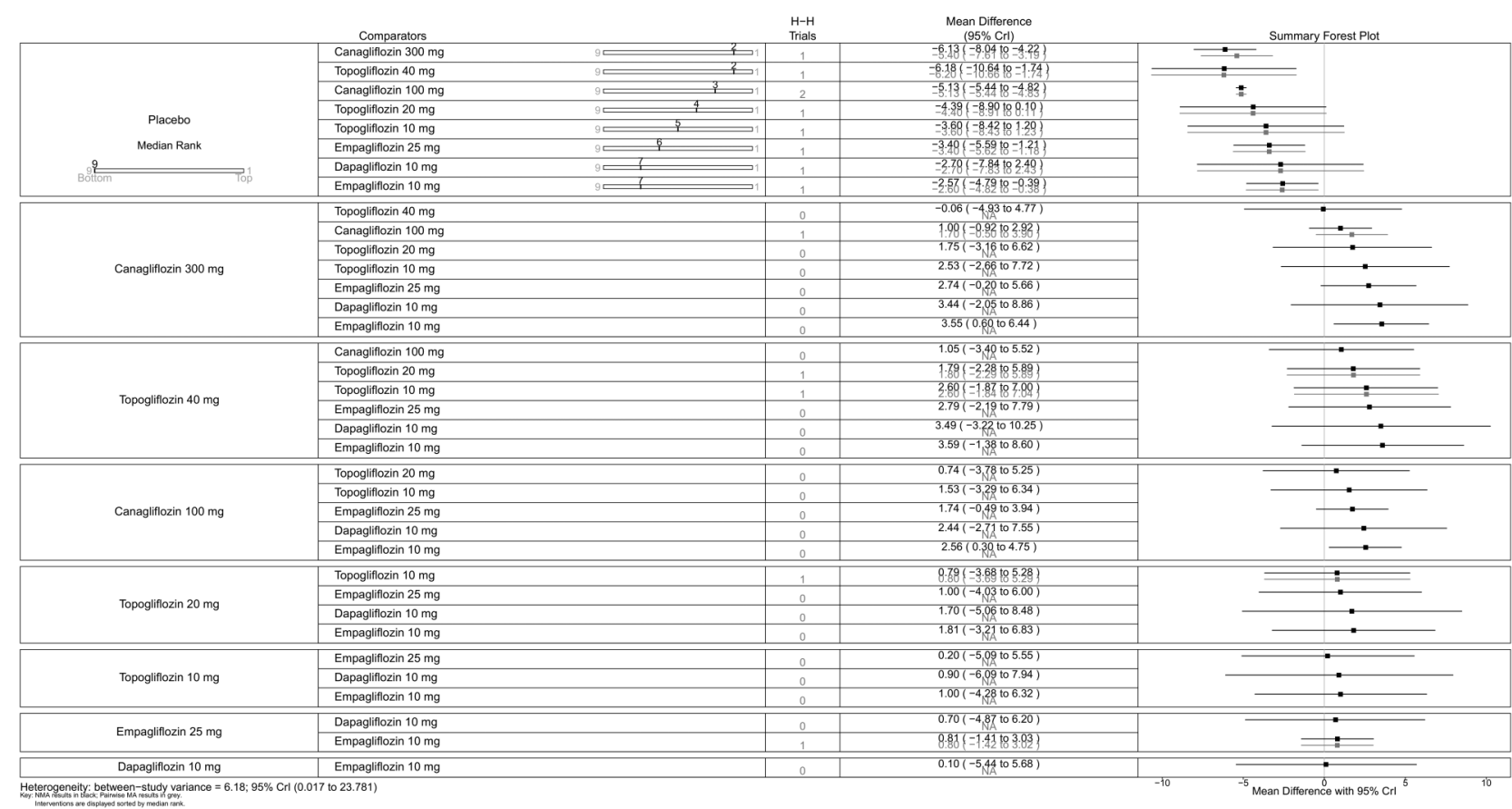

Figure 8 Mean change in SBP ( $\mathrm{mm} \mathrm{Hg}$-—monotherapy. NA, not available; NMA, network meta-analysis; SBP, systolic blood pressure. 


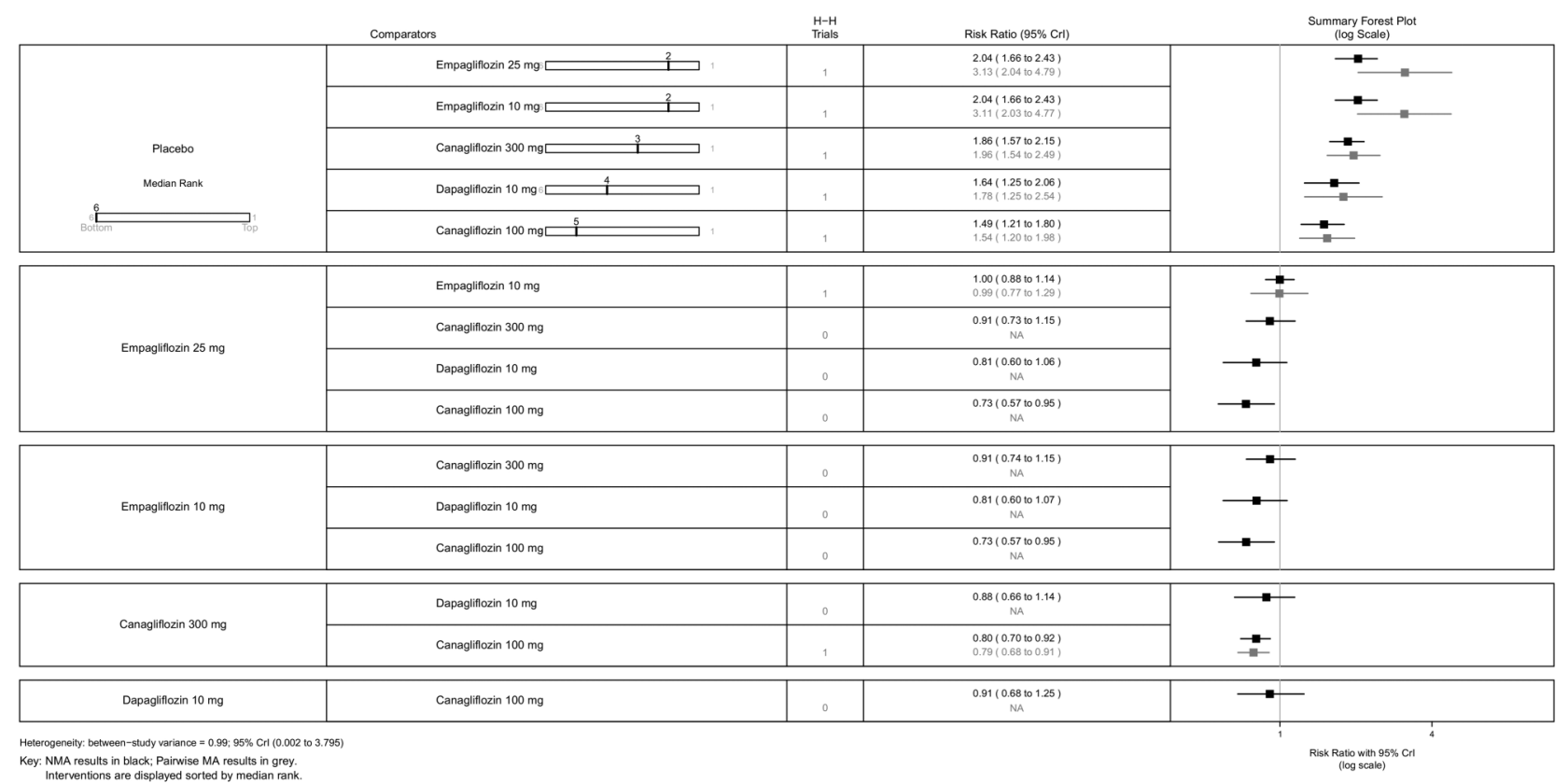

Figure 9 Proportion of patients achieving HbA1c level of $<7.0 \%$-dual therapy. HbA1c, glycated haemoglobin; NA, not available; NMA, network meta-analysis.

the placebo groups in the canagliflozin trials, HbAlc rose by $0.29 \%^{22}$ and $0.14 \%$ (Stenlof CANTATA-M). ${ }^{13}$ Ferranini et al suggested that the reduction in HbA1c in the placebo group might have been due to improved adherence to lifestyle advice in that group, but since the placebo tablets matched the dapagliflozin ones, this seems unlikely.
When interpreting weight changes, the baseline body mass indices (BMIs) need to be considered. The trials in China and Japan recruited people with BMIs in the 25-26 range, whereas the European trials had mean BMIs ranging from 28 to almost 34 .

Some of the included studies did not report data on all outcomes, and for these, we were not able to

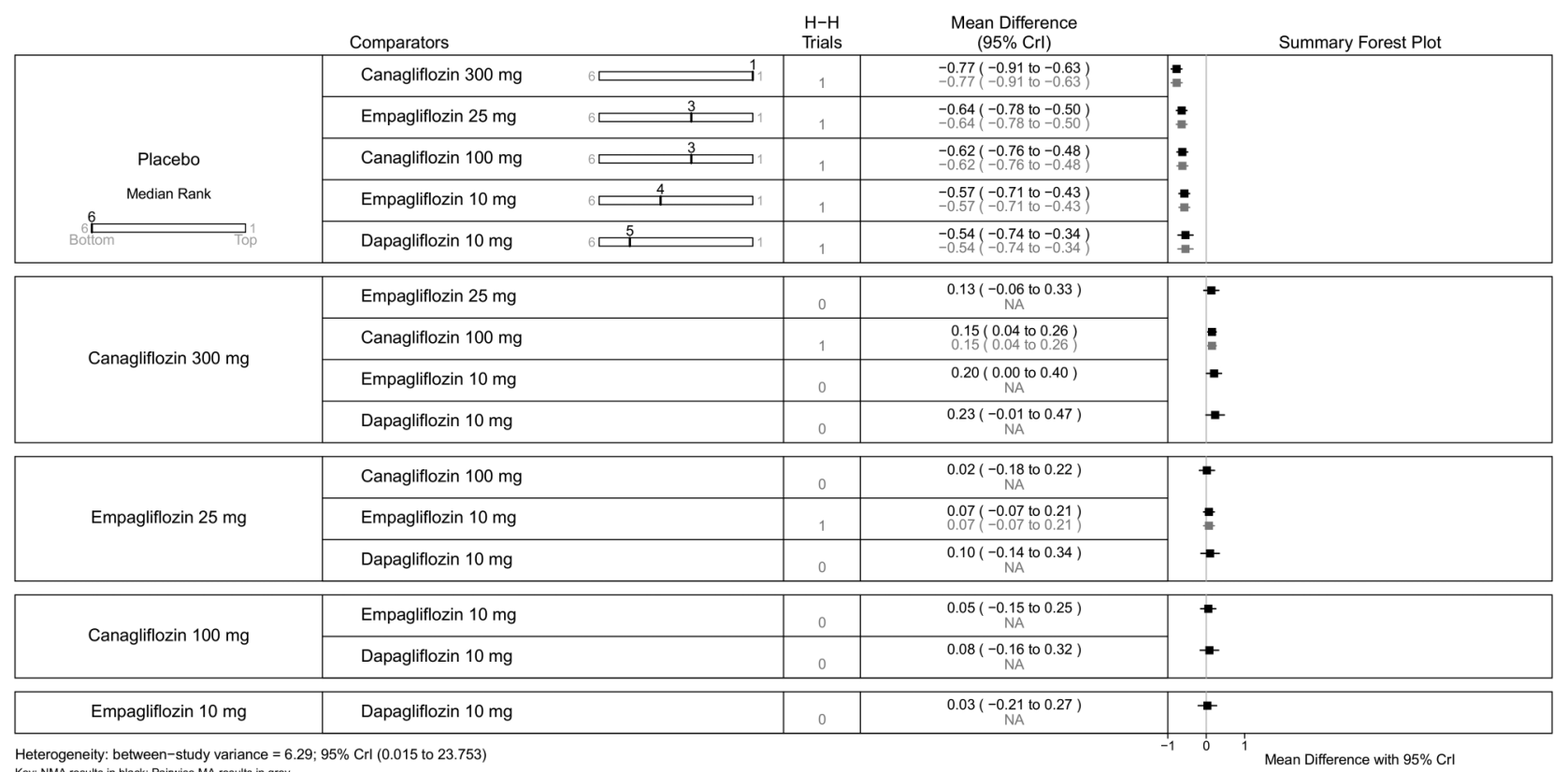

Key: NMA results in black; Pairwise MA results in grey.

Figure 10 Mean change in HbA1c (\%)—dual therapy. HbA1c, glycated haemoglobin; NA, not available; NMA, network meta-analysis. 


\begin{tabular}{|c|c|c|c|c|}
\hline & Jomparators & $\begin{array}{l}\mathrm{H}-\mathrm{H} \\
\text { Trials }\end{array}$ & $\begin{array}{l}\text { Mean untrerence } \\
(95 \% \mathrm{Crl})\end{array}$ & \multirow{6}{*}{ Summary Forest Plot } \\
\hline \multirow{5}{*}{ 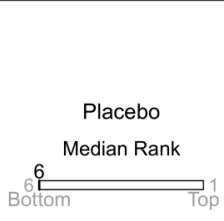 } & Canagliflozin $300 \mathrm{mg} 6{ }_{1}$ & 1 & $\begin{array}{l}-2.50(-3.05 \text { to }-1.95) \\
-2.50(-3.05 \text { to }-1.95)\end{array}$ & \\
\hline & Canagliflozin $100 \mathrm{mg} 6\left[\begin{array}{l}2 \\
1\end{array}\right.$ & 1 & $\begin{array}{l}-2.20(-2.75 \text { to }-1.66) \\
-2.20(-2.75 \text { to }-1.65)\end{array}$ & \\
\hline & 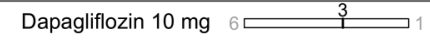 & 2 & $\left.\begin{array}{l}-2.04(-2.55 \text { to }-1.52) \\
-2.03(-2.56 \text { to }-1.51\end{array}\right)$ & \\
\hline & Empagliflozin $25 \mathrm{mg}$ 6 $\stackrel{3}{1}$ & 1 & $-2.01(-2.48$ to -1.53$)$ & \\
\hline & Empagliflozin $10 \mathrm{mg}=5$ & 1 & $-1.62(-2.10$ to -1.16$)$ & \\
\hline \multirow{4}{*}{ Canagliflozin $300 \mathrm{mg}$} & Canagliflozin $100 \mathrm{mg}$ & 1 & $0.30(-0.25$ to 0.85$)$ & $\Rightarrow$ \\
\hline & Dapagliflozin $10 \mathrm{mg}$ & 0 & $0.46(-0.30$ to 1.22$)$ & $\square$ \\
\hline & Empagliflozin $25 \mathrm{mg}$ & 0 & $0.49(-0.23$ to 1.21$)$ & $=$ \\
\hline & Empagliflozin $10 \mathrm{mg}$ & 0 & $0.87(0.15$ to 1.60$)$ & $\longrightarrow$ \\
\hline \multirow{3}{*}{ Canagliflozin $100 \mathrm{mg}$} & Dapagliflozin $10 \mathrm{mg}$ & 0 & $0.16(-0.59$ to 0.92$)$ & $\longrightarrow$ \\
\hline & Empagliflozin $25 \mathrm{mg}$ & 0 & $0.19(-0.53$ to 0.92$)$ & 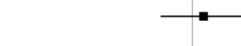 \\
\hline & Empagliflozin $10 \mathrm{mg}$ & 0 & $0.58(-0.14$ to 1.29$)$ & \\
\hline \multirow{2}{*}{ Dapagliflozin $10 \mathrm{mg}$} & Empagliflozin $25 \mathrm{mg}$ & 0 & $0.03(-0.68$ to 0.73$)$ & $\longrightarrow$ \\
\hline & Empagliflozin $10 \mathrm{mg}$ & 0 & $0.41(-0.29$ to 1.11$)$ & $\because$ \\
\hline Empagliflozin $25 \mathrm{mg}$ & Empagliflozin $10 \mathrm{mg}$ & 1 & $8.38(-0.09$ to 0.85$)$ & $=$ \\
\hline
\end{tabular}

Key: NMA results in black: Pairwise MA results in grey.
Interventions are displayed sorted by median rank.

Figure 11 Mean change in weight $(\mathrm{kg})$-dual therapy. NA, not available; NMA, network meta-analysis.

compare all the SGLT-2 inhibitors against each other. For example, the Seino $e t a l^{21}$ trial with the new SGLT-2 inhibitor, luseogliflozin, did not provide data on proportion of patients achieving HbAlc level of $<7 \%$ and mean change in SBP.

The primary outcomes of both canagliflozin studies were reported at 26 weeks instead of 24 weeks. Therefore, we assumed that the effect of canagliflozin measured at 26 weeks was comparable against other SGLT-2 inhibitors, which reported results at 24 weeks.
The numbers of patients in each centre were often small, such as means of 3.2 patients per centre in the Ferranini trial and 4.5 in the Bolinder one. This must raise questions about how typical the recruits were. We did not compare safety data.

\section{Meaning of the study}

In the absence of head-to-head comparison of SGLT-2 inhibitors in patients with type 2 diabetes inadequately controlled with diet and exercise or metformin, this

\begin{tabular}{|c|c|c|c|c|c|}
\hline \multicolumn{2}{|r|}{ Comparators } & $\begin{array}{l}n \\
-\pi \\
\text { Trials }\end{array}$ & $\begin{array}{l}\text { iviealı villeieilue } \\
(95 \% \mathrm{Crl})\end{array}$ & \multicolumn{2}{|c|}{ Summary Forest Plot } \\
\hline \multirow{4}{*}{$\begin{array}{c}\text { Placebo } \\
\text { Bedian Rank } \\
5^{5 \overbrace{}^{\text {Motom }}}\end{array}$} & Canagliflozin $300 \mathrm{mg} \quad 5 \square{ }_{1}^{1}$ & 1 & $\begin{array}{l}-6.60(-8.57 \text { to }-4.66 \\
-6.60\end{array}(-8.55$ to -4.65$)$ & \multirow{4}{*}{$\begin{array}{l}\square \\
\square\end{array}$} & \\
\hline & Canagliflozin $1 0 0 \mathrm { mg } 5 \longdiv { 2 }$ & 1 & 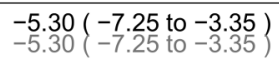 & & \\
\hline & Empagliflozin $25 \mathrm{mg} 5 \square$ & 1 & $\left.\begin{array}{l}-4.79(-6.73 \text { to }-2.85) \\
-4.80(-6.74 \text { to }-2.86\end{array}\right)$ & & \\
\hline & Empagliflozin $10 \mathrm{mg} \quad 5 \square 4$ & 1 & $\left.\begin{array}{l}-4.09(-6.04 \text { to }-2.16 \\
-4.10 \\
-6.04 \text { to }-2.16\end{array}\right)$ & & \\
\hline \multirow{3}{*}{ Canagliflozin $300 \mathrm{mg}$} & Canagliflozin $100 \mathrm{mg}$ & 1 & $\left.\begin{array}{l}1.30(-0.35 \text { to } 2.95 \\
1.30 \\
-0.35 \text { to } 2.95\end{array}\right)$ & & $\square$ \\
\hline & Empagliflozin $25 \mathrm{mg}$ & 0 & $1.81(-0.92$ to 4.56$)$ & & \\
\hline & Empagliflozin $10 \mathrm{mg}$ & 0 & $2.52(-0.22$ to 5.28$)$ & & \\
\hline \multirow{2}{*}{ Canagliflozin $100 \mathrm{mg}$} & Empagliflozin $25 \mathrm{mg}$ & 0 & $0.51(-2.20$ to 3.26$)$ & \multicolumn{2}{|c|}{$\longrightarrow$} \\
\hline & Empagliflozin $10 \mathrm{mg}$ & 0 & $\begin{array}{c}1.21(-1.53 \text { to } 3.95) \\
\text { NA }\end{array}$ & & $\rightarrow$ \\
\hline Empagliflozin $25 \mathrm{mg}$ & Empagliflozin $10 \mathrm{mg}$ & 1 & $\begin{array}{l}0.69(-1.26 \text { to } 2.63 \\
0.70(-1.24 \text { to } 2.64)\end{array}$ & \multicolumn{2}{|r|}{$\square$} \\
\hline
\end{tabular}

Figure 12 Mean change in SBP ( $\mathrm{mm} \mathrm{Hg}$ )—dual therapy. NA, not available; NMA, network meta-analysis; SBP, systolic blood pressure. 


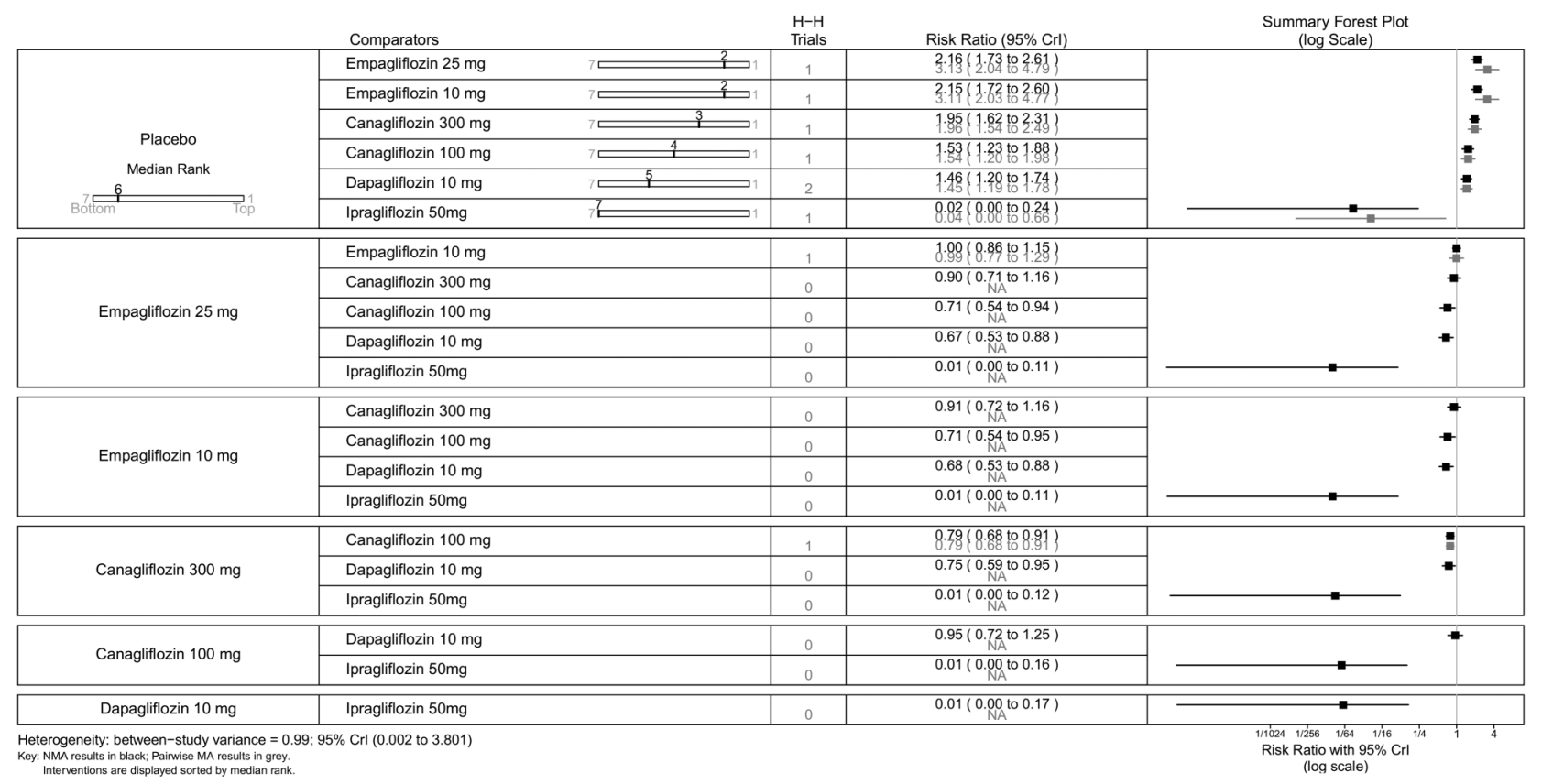

Figure 13 Proportion of patients achieving $\mathrm{HbA} 1 \mathrm{c}$ level of $<7.0 \%$ (dual therapy), sensitivity analysis including Henry et al ${ }^{12}$ and Kashiwagi et al. ${ }^{24} \mathrm{HbA} 1 \mathrm{c}$, glycated haemoglobin; NA, not available; NMA, network meta-analysis.

study examines the evidence as to whether any drug is better than others. NICE has approved dapagliflozin $10 \mathrm{mg}$ as an option for the treatment of diabetes in combination with metformin or as an add-on to insulin with or without other glucose-lowering drugs. ${ }^{1}$ NICE has approved canagliflozin as dual therapy (in combination with metformin if sulfonylurea is contraindicated) or triple therapy (in combination with metformin plus sulfonylurea or metformin plus thiazolidinediones) or as add on to insulin with or without other antidiabetic drugs. ${ }^{2}$ Empagliflozin has also been approved by NICE in combination therapy. ${ }^{3}$

The usual first drug for type 2 diabetes is metformin, with sulfonylurea in those who cannot tolerate

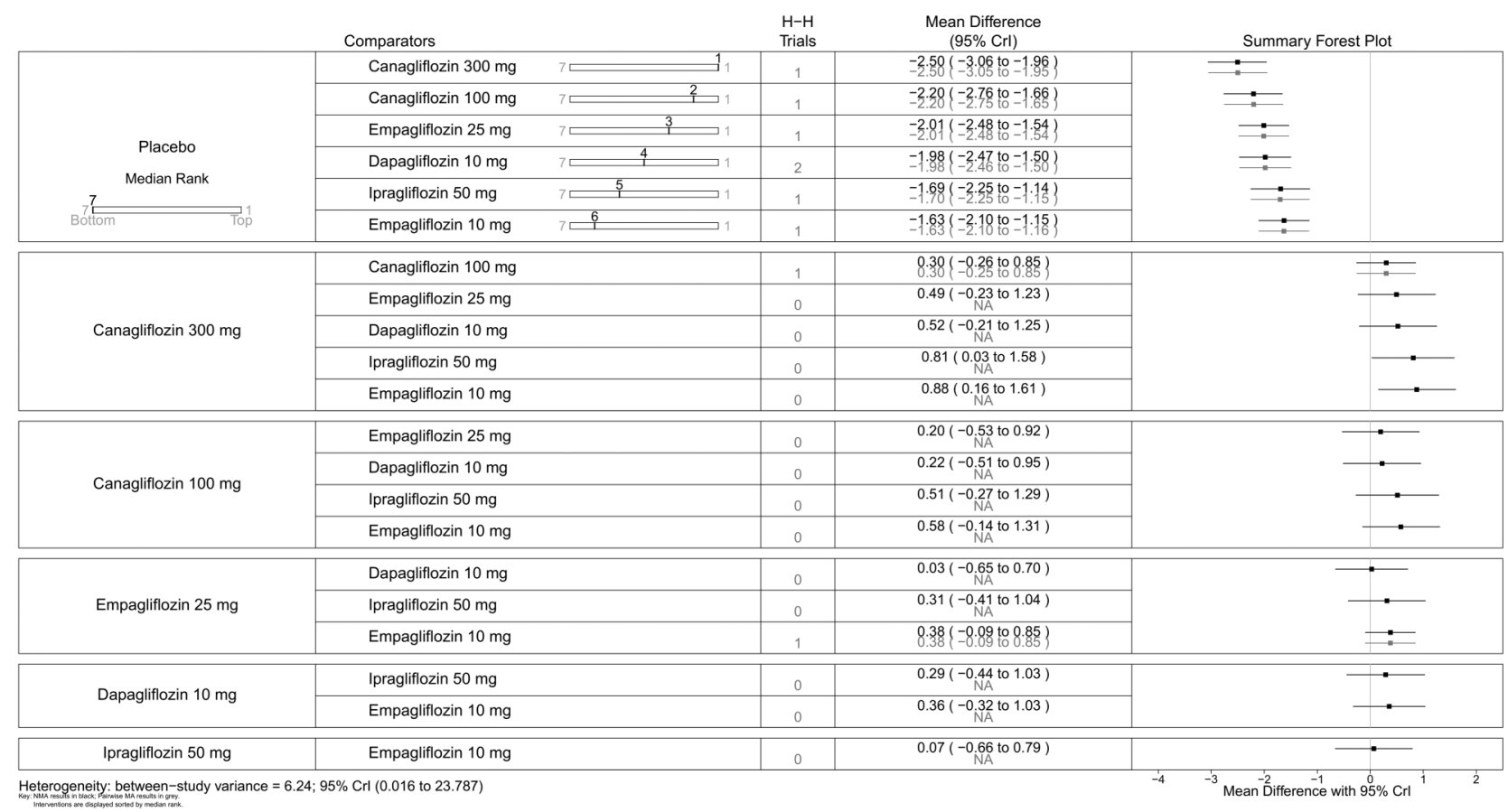

Figure 14 Mean change in weight (kg; dual therapy), sensitivity analysis including Bolinder et al, ${ }^{11}$ Henry et all 2012 and Kashiwagi et al. ${ }^{24} \mathrm{NA}$, not available; NMA, network meta-analysis. 


\begin{tabular}{|c|c|c|c|c|c|c|}
\hline & Comparators & & $\begin{array}{l}\mathrm{H}-\mathrm{H} \\
\text { Trials } \\
\mathrm{T}\end{array}$ & $\begin{array}{l}\text { Mean Difference } \\
(95 \% \text { Crll) }\end{array}$ & \multicolumn{2}{|c|}{ Summary Forest Plot } \\
\hline \multirow{6}{*}{$\begin{array}{l}\text { Placebo } \\
\text { Modien Rerk }\end{array}$} & Dapagiffozin $10 \mathrm{mg}$ & $\longrightarrow$ & 1 & $\begin{array}{l}-1.25(-1.4770-1.02) \\
-1.25(-1.4710-1.03)\end{array}$ & \multirow{6}{*}{$\begin{aligned} \because & \\
& = \\
& = \\
& = \\
& = \\
& =\end{aligned}$} & \\
\hline & |pragliflozin $50 \mathrm{mg}$ & (2) & 1 & $\begin{array}{l}-0.77(-0.9110-0.69) \\
-0.77(-0.9110-0.039)\end{array}$ & & \\
\hline & Canaglifozin $300 \mathrm{mg}$ & $\stackrel{3}{1}$ & 1 & $\begin{array}{l}-0.64(-0.7810-0.50) \\
-0.64(-0.7810-0.50)\end{array}$ & & \\
\hline & Empagiflozin $25 \mathrm{mg}$ & ! & 1 & $\begin{array}{l}-0.62(-0.766-0.48) \\
-0.02(-0.7610-0.48)\end{array}$ & & \\
\hline & Canaglifozin $100 \mathrm{mg}$ & $\stackrel{5}{1}$ & 1 & $\begin{array}{l}-0.57(-0.716-0.43) \\
-0.57(-0.7110-0.43)\end{array}$ & & \\
\hline & Empagiflifozin $10 \mathrm{mg}$ & $\stackrel{6}{1}$ & 3 & $\begin{array}{l}-0.41(-0.5010-0.31) \\
-0.44(-0.5010-0.31)\end{array}$ & & \\
\hline \multirow{5}{*}{ Dapaglitlozin $10 \mathrm{mg}$} & Ipragilifozin $50 \mathrm{mg}$ & & 0 & $-2.09(-4.7340-1.35)$ & \multirow{5}{*}{\multicolumn{2}{|c|}{$\begin{array}{l}\rightarrow \\
-- \\
= \\
\rightarrow \\
\rightarrow\end{array}$}} \\
\hline & Canaglifozin $300 \mathrm{mg}$ & & 。 & $-1.64(-2.9210-1.15)$ & & \\
\hline & Empagiflifozin $25 \mathrm{mg}$ & & 。 & $\begin{array}{l}-1.59(-2.7710-1.12) \\
N A\end{array}$ & & \\
\hline & Canaglifinozin $100 \mathrm{mg}$ & & 0 & $\begin{array}{l}-1.47(-2.4110-1.06) \\
\mathrm{NA}\end{array}$ & & \\
\hline & Empagiflitozin $10 \mathrm{mg}$ & & 0 & $-1.18(-1.5710-0.92)$ & & \\
\hline \multirow{4}{*}{ |pragliflozin $50 \mathrm{mg}$} & Canaglifozin $300 \mathrm{mg}$ & & 。 & $\begin{array}{l}0.13(-0.0770 .33) \\
N A\end{array}$ & \multirow{4}{*}{\multicolumn{2}{|c|}{$\begin{array}{l}= \\
= \\
= \\
-\end{array}$}} \\
\hline & Empagitiflozin $25 \mathrm{mg}$ & & 1 & 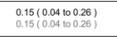 & & \\
\hline & Canaglifozin $100 \mathrm{mg}$ & & 0 & $0.20(0.00$ t to 0.40$)$ & & \\
\hline & Empagifilozin $10 \mathrm{mg}$ & & 0 & $\begin{array}{l}0.36(0.19100 .53) \\
\mathrm{NA}\end{array}$ & & \\
\hline \multirow{3}{*}{ Canagilitozin $300 \mathrm{mg}$} & Empagifilozin $25 \mathrm{mg}$ & & 0 & $0.02(-0.18100 .22)$ & \multirow{3}{*}{\multicolumn{2}{|c|}{$\begin{array}{l}\because \\
\because-\end{array}$}} \\
\hline & Canaglifozin $100 \mathrm{mg}$ & & 1 & $\begin{array}{l}0.07(-0.0710021\} \\
0.07(-0.0710021)\end{array}$ & & \\
\hline & Empagititlozin $10 \mathrm{mg}$ & & 0 & $\begin{array}{l}023(0.0660 .41) \\
N A\end{array}$ & & \\
\hline \multirow{2}{*}{ Empagintlozin $25 \mathrm{mg}$} & Canaglifozin $100 \mathrm{mg}$ & & 。 & $0.05(-0.15150 .025)$ & \multirow{2}{*}{\multicolumn{2}{|c|}{$\cdot-$}} \\
\hline & Empagifitlozin $10 \mathrm{mg}$ & & $\circ$ & $\begin{array}{l}021(0.04 t 00.39) \\
\text { NaA }\end{array}$ & & \\
\hline Canaglifozin $100 \mathrm{mg}$ & Empagifilozin $10 \mathrm{mg}$ & & 0 & $0.16(-0.00100 .33)$ & \multicolumn{2}{|c|}{$\rightarrow$} \\
\hline
\end{tabular}

Figure 15 Mean change in SBP ( $\mathrm{mm} \mathrm{Hg}$; dual therapy), sensitivity analysis including Kashiwagi et al. ${ }^{24} \mathrm{NA}$, not available; NMA, network meta-analysis; SBP, systolic blood pressure.

metformin. NICE is appraising the use of the flozins in monotherapy in people who cannot take metformin in $2015 .{ }^{27}$ It has been pointed out that the flozins are the only oral glucose-lowering drugs that are associated with weight reduction.

A recent mixed treatment comparison, available in abstract only at present, ${ }^{28}$ compared the efficacy and safety of canagliflozin in dual therapy (in combination with metformin) using a Bayesian approach against sulfonylureas, pioglitazone, dipeptidyl peptidase-4 (DPP-4) inhibitors, glucagon-like peptide-1 (GLP-1) analogues and dapagliflozin. The outcomes compared were HbA1c, weight and hypoglycaemia at 26, 52 and 104 weeks. Pacou et al reported that both canagliflozin 100 and $300 \mathrm{mg}$ led to larger reductions in HbAlc level than with DPP-4 inhibitors and dapagliflozin but similar

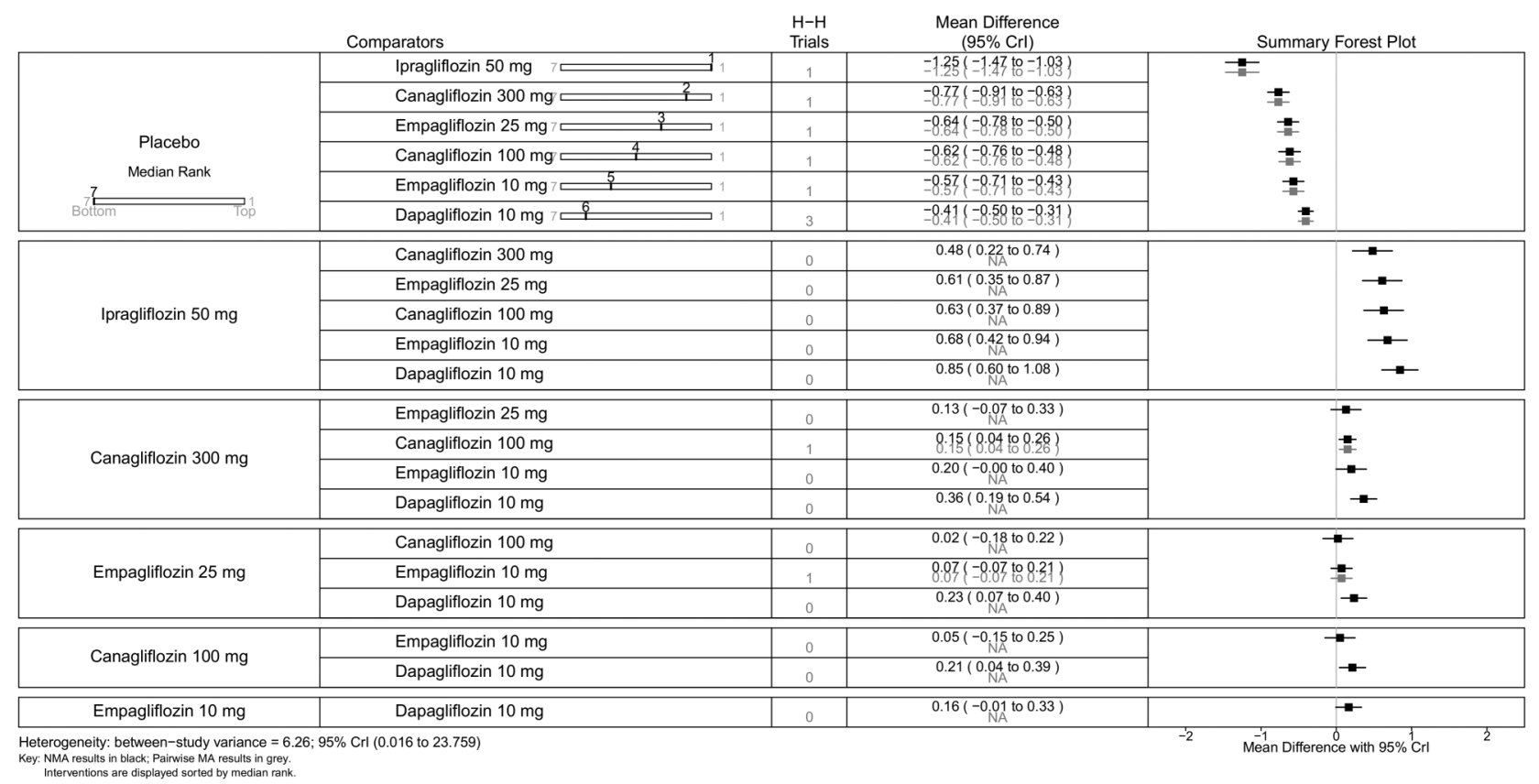

Figure 16 Mean change in $\mathrm{HbA} 1 \mathrm{c}$ (\%; dual therapy), sensitivity analysis including Bolinder et $a l,{ }^{11}$ Henry et all ${ }^{12}$ and Kashiwagi et al. ${ }^{24} \mathrm{HbA} 1 \mathrm{c}$, glycated haemoglobin; NA, not available; NMA, network meta-analysis. 
reduction in HbAlc to liraglutide over 104 weeks. The weight reduction was also comparable to GLP-1 analogues. Hypoglycaemia was less frequent with all SGLT-2 inhibitors compared with sulfonylureas. The mixed treatment comparison undertaken by Pacou et al (most of whom are associated with Janssen, the manufacturers of canagliflozin) was not available in full, so we were not able to determine which studies were included or to assess the quality of the study.

Our initial question was whether canagliflozin is more potent than other SGLT-2 inhibitors, due to its dual effect on SGLT-2 and SGLT-1 receptors. In monotherapy, both doses of canagliflozin lowered HbA1c slightly more than both doses of empagliflozin, which does not have significant effects on SGLT-1 receptors. These differences were not seen in dual therapy. This suggests that the SGLT-1 effect may not be clinically significant.

There are still unanswered questions. We do not know how long SGLT-2 inhibitors would be effective for, but as the mode of action is independent of insulin release, one might expect them to be effective irrespective of diabetes duration. Women taking these drugs have increases in urinary tract and genital tract infection but these are reported in the trials to be mild in intensity. At present, we do not know if there are long-term adverse effects, either from the class as a whole or from individual drugs. There has been recent concern about diabetic ketoacidosis among people on the SGLT-2 inhibitors. ${ }^{29} 30$

\section{CONCLUSION}

There are few clinically significant differences among the drugs. In monotherapy, reductions in HbAlc were largest with canagliflozin and smallest with dapagliflozin. Differences in HbAlc were insignificant in dual therapy.

\section{Author affiliations}

${ }^{1}$ Warwick Medical School, Coventry, UK

${ }^{2}$ Division of Health Sciences, Centre for Applied Health Research and Delivery (WCAHRD), Warwick Medical School, Coventry, UK

${ }^{3}$ Public Health Medicine and Health Technology Assessment Warwick Medical School, Coventry, UK

Contributors NW and DSS conceived the study. DSS carried out the systematic review, assisted by NW. OAU carried out the network meta-analysis. All authors were involved in writing the manuscript.

Funding This research received no specific grant from any funding agency in the public, commercial or not-for-profit sectors.

Competing interests DSS has joined Eli Lilly but was employed by the University of Warwick when this review was undertaken. DSS carried out this work while in Warwick Medical School. DSS and NW were involved in the NICE STA on empagliflozin in combination therapy; NW was involved in the NICE STA of dapagliflozin in combination therapy; and OAU and NW are involved in the NICE appraisal of canagliflozin, dapagliflozin and empaglifozin in monotherapy for type 2 diabetes.

Provenance and peer review Not commissioned; externally peer reviewed. Data sharing statement No additional data are available.

Open Access This is an Open Access article distributed in accordance with the Creative Commons Attribution Non Commercial (CC BY-NC 4.0) license, which permits others to distribute, remix, adapt, build upon this work non- commercially, and license their derivative works on different terms, provided the original work is properly cited and the use is non-commercial. See: http:// creativecommons.org/licenses/by-nc/4.0/

\section{REFERENCES}

1. National Institute for Health and Care Excellence. NICE Guidance TA288. Dapagliflozin in combination therapy for treating type 2 diabetes. Secondary NICE Guidance TA288. Dapagliflozin in combination therapy for treating type 2 diabetes. 2013. http://www. nice.org.uk/guidance/TA288/chapter/1-guidance

2. National Institute for Health and Care Excellence. NICE Guidance TA315. Canagliflozin in combination therapy for treating type 2 diabetes. Secondary NICE Guidance TA315. Canagliflozin in combination therapy for treating type 2 diabetes 2014. http://www. nice.org.uk/guidance/TA315/chapter/1-guidance

3. National Institute for Health and Care Excellence. Empagliflozin combination therapy for treating type 2 diabetes [ID641] GID-TAG441. Secondary Empagliflozin combination therapy for treating type 2 diabetes [ID641] GID-TAG441 2014. http://www.nice. org.uk/guidance/indevelopment/GID-TAG441

4. Polidori D, Sha S, Mudaliar S, et al. Canagliflozin lowers postprandial glucose and insulin by delaying intestinal glucose absorption in addition to increasing urinary glucose excretion results of a randomized, placebo-controlled study. Diabetes Care 2013;36:2154-61

5. Stein P, Berg JK, Morrow L, et al. Canagliflozin, a sodium glucose co-transporter 2 inhibitor, reduces post-meal glucose excursion in patients with type 2 diabetes by a non-renal mechanism: results of a randomized trial. Metab Clin Exp 2014;63:1296-303.

6. Higgins J, Green S, Collaboration TC. Cochrane Handbook for Systematic Reviews of Interventions Version 5.1.0 [updated March 2011]. Secondary Cochrane Handbook for Systematic Reviews of Interventions Version 5.1.0 [updated March 2011]. 2011. http://www. cochrane.org/handbook

7. Veroniki AA, Vasiliadis HS, Higgins JP, et al. Evaluation of inconsistency in networks of interventions. Int $J$ Epidemiol 2013;42:332-45.

8. Jansen JP, Naci $\mathrm{H}$. Is network meta-analysis as valid as standard pairwise meta-analysis? It all depends on the distribution of effect modifiers. BMC Med 2013;11:159.

9. Higgins JPT, Jackson D, Barrett JK, et al. Consistency and inconsistency in network meta-analysis: concepts and models for multi-arm studies. Res Synth Methods 2012;3:98-110.

10. Dias S, Welton NJ, Caldwell DM, et al. Checking consistency in mixed treatment comparison meta-analysis. Stat Med 2010;29:932-44.

11. Bolinder J, Ljunggren $\mathrm{O}$, Kullberg J, et al. Effects of dapagliflozin on body weight, total fat mass, and regional adipose tissue distribution in patients with type 2 diabetes mellitus with inadequate glycemic control on metformin. J Clin Endocrinol Metab 2012;97:1020-31.

12. Henry RR, Murray AV, Marmolejo MH, et al. Dapagliflozin, metformin $X R$, or both: initial pharmacotherapy for type 2 diabetes, a randomised controlled trial. Int J Clin Pract 2012;66:446-56.

13. Stenlof K, Cefalu WT, Kim KA, et al. Efficacy and safety of canagliflozin monotherapy in subjects with type 2 diabetes mellitus inadequately controlled with diet and exercise. Diabetes Obes Metab 2013;15:372-82.

14. Bailey CJ, Gross JL, Pieters A, et al. Effect of dapagliflozin in patients with type 2 diabetes who have inadequate glycaemic contro with metformin: a randomised, double-blind, placebo-controlled trial. Lancet 2010;375:2223-33.

15. Ferrannini E, Ramos SJ, Salsali A, et al. Dapagliflozin monotherapy in type 2 diabetic patients with inadequate glycemic control by diet and exercise: a randomized, double-blind, placebo-controlled, phase 3 trial. Diabetes Care 2010;33:2217-24.

16. Haring HU, Merker L, Seewaldt-Becker E, et al. Empagliflozin as add-on to metformin in patients with type 2 diabetes: a 24-week, randomized, double-blind, placebo-controlled trial. Diabetes Care 2014;37:1650-9.

17. Ji L, Ma J, Li H, et al. Dapagliflozin as monotherapy in drug-naive Asian patients with type 2 diabetes mellitus: a randomized, blinded, prospective phase III study. Clin Ther 2014;36:84-100.e9.

18. Kaku K, Kiyosue A, Inoue S, et al. Efficacy and safety of dapagliflozin monotherapy in Japanese patients with type 2 diabetes inadequately controlled with diet and exercise. Diabetes Obes Metab 2013;15:432-40.

19. Lavalle-Gonzalez FJ, Januszewicz A, Davidson J, et al. Efficacy and safety of canagliflozin compared with placebo and sitagliptin in 
patients with type 2 diabetes on background metformin monotherapy: a randomised trial. Diabetologia 2013;56:2582-92.

20. Roden M, Weng J, Eilbracht J, et al. Empagliflozin monotherapy with sitagliptin as an active comparator in patients with type 2 diabetes: a randomised, double-blind, placebo-controlled, phase 3 trial. Lancet Diabetes Endocrinol 2013;1:208-19.

21. Seino $Y$, Sasaki T, Fukatsu A, et al. Efficacy and safety of luseogliflozin as monotherapy in Japanese patients with type 2 diabetes mellitus: a randomized, double-blind, placebo-controlled, phase 3 study. Curr Med Res Opin 2014;30:1245-55.

22. Inagaki N, Kondo K, Yoshinari T, et al. Efficacy and safety of canagliflozin monotherapy in Japanese patients with type 2 diabetes inadequately controlled with diet and exercise: a 24-week, randomized, double-blind, placebo-controlled, Phase III study. Expert Opin Pharmacother 2014;15:1501-15.

23. Kaku K, Watada $\mathrm{H}$, Iwamoto $\mathrm{Y}$, et al. Efficacy and safety of monotherapy with the novel sodium/glucose cotransporter-2 inhibitor tofogliflozin in Japanese patients with type 2 diabetes mellitus: a combined phase 2 and 3 randomized, placebo-controlled, double-blind, parallel-group comparative study. Cardiovasc Diabetol 2014;13:65.

24. Kashiwagi A, Kazuta K, Goto K, et al. Ipragliflozin in combination with metformin for the treatment of Japanese patients with type 2 diabetes: ILLUMINATE, a randomized, double-blind, placebo-controlled study. Diabetes Obes Metab 2015;17: 304-8.

25. Cooper NJ, Peters J, Lai MC, et al. How valuable are multiple treatment comparison methods in evidence-based health-care evaluation? Value Health 2011;14:371-80.

26. Thorlund K, Mills EJ. Sample size and power considerations in network meta-analysis. Syst Rev 2012;1:41.

27. National Institute for Health and Care Excellence. Canagliflozin, dapagliflozin and empagliflozin monotherapy for treating type 2 diabetes [ID756] GID-TAG471. Secondary canagliflozin, dapagliflozin and empagliflozin monotherapy for treating type 2 diabetes [ID756] GID-TAG471 2015. http://www.nice.org.uk/ guidance/indevelopment/GID-TAG471

28. Pacou M, Taieb V, Abrams KR, et al. Bayesian network meta-analysis to assess relative efficacy and safety of canagliflozin in patients with type 2 diabetes mellitus (T2DM) inadequately controlled with metformin. Value Health 2013;16:A609.

29. Taylor SI, Blau JE, Rother KI. SGLT2 inhibitors may predipose to ketoacidosis. J Clin Endocrinol Metab 2015;100:2849-52.

30. Peters AL, Buschur EO, Buse JB, et al. Euglycemic diabetic ketoacidosis: a potential complication of treatment with sodium-glucose cotransported 2 inhibition. Diabetes Care 2015;38:1687-93. 